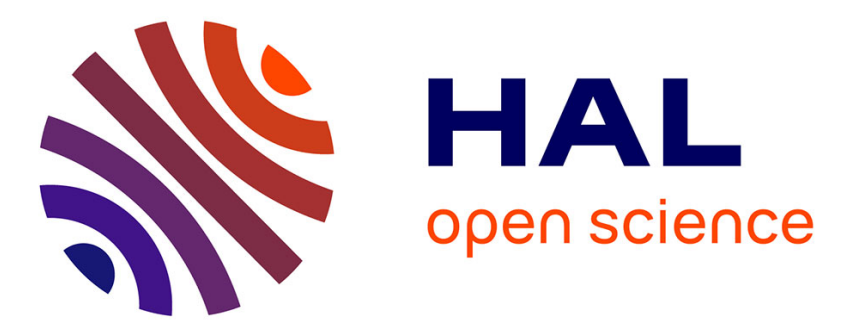

\title{
Control of Structures and Emission Properties of (CuI) n 2-Methyldithiane Coordination Polymers
}

\author{
Adrien Schlachter, Lydie Viau, Daniel Fortin, Lena Knauer, Carsten \\ Strohmann, Michael Knorr, Pierre Harvey
}

\section{To cite this version:}

Adrien Schlachter, Lydie Viau, Daniel Fortin, Lena Knauer, Carsten Strohmann, et al.. Control of Structures and Emission Properties of (CuI) n 2-Methyldithiane Coordination Polymers. Inorganic Chemistry, 2018, 57 (21), pp.13564 - 13576. 10.1021/acs.inorgchem.8b02168 . hal-01935183

\section{HAL Id: hal-01935183 \\ https://hal.science/hal-01935183}

Submitted on 14 Jan 2022

HAL is a multi-disciplinary open access archive for the deposit and dissemination of scientific research documents, whether they are published or not. The documents may come from teaching and research institutions in France or abroad, or from public or private research centers.
L'archive ouverte pluridisciplinaire $\mathbf{H A L}$, est destinée au dépôt et à la diffusion de documents scientifiques de niveau recherche, publiés ou non, émanant des établissements d'enseignement et de recherche français ou étrangers, des laboratoires publics ou privés. 


\title{
Control of Structures and Emission Properties of $(\mathrm{CuI})_{\mathrm{n}}$ 2-Methyldithiane Coordination Polymers
}

\author{
Adrien Schlachter, ${ }^{a}$ Lydie Viau, ${ }^{* b}$ Daniel Fortin, ${ }^{a}$ Lena Knauer, ${ }^{c}$ Carsten Strohmann, ${ }^{c}$ Michael \\ Knorr, ${ }^{b}$ and Pierre D. Harvey ${ }^{a} *$ \\ a Département de Chimie, Université de Sherbrooke, Sherbrooke, Québec, Canada J1K 2R1. \\ b Institut UTINAM UMR CNRS 6213, Université Bourgogne Franche-Comté, 25030 Besançon, \\ France. \\ ${ }^{c}$ Anorganische Chemie, Technische Universität Dortmund, Otto-Hahn-Strasse 6, 44227 \\ Dortmund, Germany
}

\begin{abstract}
A structurally unique and strongly luminescent non-porous 3D coordination polymer $(\mathrm{CP})\left[\mathrm{Cu}_{8} \mathrm{I}_{8}(\text { methyldithiane })_{4}\right]_{\mathrm{n}}, \mathbf{C P 3}$, has been prepared in a quasi-anticipated manner from 2-methyl-1,3-dithiane, $\mathbf{L 1}$, and CuI. This CP incorporates the unprecedented $\mathrm{Cu}_{8} \mathrm{I}_{8}$ cluster built upon two side-fused open cubanes. The crystal structure of CP3 has been determined at $100,150,200,250,300,350$ and $400 \mathrm{~K}$ to study the temperature dependence of the $\mathrm{Cu} \cdots \mathrm{Cu}$ distances. Two other topological $1 \mathrm{D}$ and 2D CPs isomers of formula $\left[\left\{\mathrm{Cu}_{2} \mathrm{I}_{2}\right\}(\mathbf{L 1})_{2}\right]_{\mathrm{n}}$ featuring dinuclear $\left\{\mathrm{Cu}_{2}\left(\mu_{2}-\mathrm{I}\right)_{2}\right\}$ rhomboids were also obtained independently by control of the reaction conditions. These two CPs convert into CP3 in hot PrCN thus indicating that this latter material is the thermodynamic product. While CP1 and CP2 are not emissive, CP3 exhibits an intense luminescence due to the incorporation of the octanuclear $\mathrm{Cu}_{8} \mathrm{I}_{8}$ clusters as secondary building units (SBUs) within the network. The photophysical properties of CP3 have been investigated and rationalized by means of DFT and TDDFT computing. Furthermore, the thermal stability of these materials has been studied by ATG and DSC analyses. The Raman spectra of CP1-3 have been recorded in the solid state in the $50-500 \mathrm{~cm}^{-1}$ region.
\end{abstract}




\section{INTRODUCTION}

The design of coordination polymers with a predictable secondary building unit (SBU) and dimensionality is a quasi-impossible task but the quest remains of great interest for the discovery of new materials with desired properties such as gas adsorption, ${ }^{1-9}$ sensing, ${ }^{10-15}$ thermochromism, ${ }^{16-19}$ magnetism, ${ }^{20-24}$ conductivity, ${ }^{25-28}$ redox-activity, ${ }^{29,} 30$ catalysis, ${ }^{13,}{ }^{31-33}$ nonlinear optical behavior $^{34,35}$ and luminescence. ${ }^{8,36-40}$ Recent reviews on CPs formed by mono- and dithioethers with $\mathrm{CuX}$ salts $(\mathrm{X}=\mathrm{Cl}, \mathrm{Br}, \mathrm{I})^{41-47}$ revealed that when $\mathrm{X}=\mathrm{I}$, the SBU had a strong tendency to form closed cubanes $\left(\mathrm{Cu}_{4} \mathrm{I}_{4}\right)$ and 1D staircase polymeric structures, whereas the rhomboid $\mathrm{Cu}_{2} \mathrm{X}_{2} \mathrm{~S}_{4} \mathrm{SBU}$ is predominately noted when $\mathrm{X}=\mathrm{Cl}$ or $\mathrm{Br}$. The key property is that the cubanes show luminescence regardless of the ligand whereas the rhomboids and staircase motifs are almost always weakly or not emissive. ${ }^{41,44,45}$ Also, the presence of 2D and 3D CPs increases drastically when semi-rigid or rigid dithioethers are used as assembling ligands. ${ }^{41,44,45}$ The interest in 2D and 3D CPs stems from the possibility to form MOF-like materials. ${ }^{48}$ Based on these statistics, one can expect to form emissive cubane-containing $2 \mathrm{D}$ or 3D CPs when using $\mathrm{X}$ $=\mathrm{I}$ and $\mathrm{L}=$ rigid dithioether. This hypothesis was recently tested by one of us by reacting $\mathrm{CuI}$ with trans-Pt $\left(\mathrm{PMe}_{3}\right)_{2}\left(\mathrm{C} \equiv \mathrm{CC}_{6} \mathrm{H}_{4} \mathrm{SMe}\right)_{2}$, [Pt $]$, leading to a porous emissive 2D CP, $\left(\mathrm{Cu}_{4} \mathrm{I}_{4}([\mathrm{Pt}])\right)_{\mathrm{n}}$, where the SBU is a staircase tetramer (i.e. completely open cubane). ${ }^{49,50}$ The $\mathrm{CP}$ exhibits a grid structure with small guests in the cavities $\left(\mathrm{MeOH}, \mathrm{MeCN}, \mathrm{CO}_{2} \ldots\right)$. These reviews ${ }^{41,44,45}$ also indicated the particularly rare occurrence of $\mathrm{Cu}_{8} \mathrm{I}_{8}$ clusters called fused dicubanes which account for $<5 \%$ of all thioether/cubane-containing materials (top left, Chart 1). Considering all fused neutral dicubanes reported in the literature (only 12 cases regardless the nature of the ligand), two common features appear. Most of them are included within 2D or 3D networks and are built with rigid, specifically DABCO (1,4-diazabicyclo[2.2.2]octane), or semi-rigid ligands, and are emissive ${ }^{51-58}$ However, exceptions exist. Two 0D complexes employ the monodentate ligands $\mathrm{PPh}_{2}\left(\mathrm{C}_{6} \mathrm{H}_{4} \mathrm{NMe}_{2}\right)$ and $\mathrm{S}(\mathrm{i}-\mathrm{Pr})_{2},{ }^{59,}{ }^{60}$ and for two other cases, the CPs use the flexible $p$ TolS $\left(\mathrm{CH}_{2}\right)_{8} \mathrm{STol}-p$ ligand. ${ }^{61,62}$ Other motifs for neutral $\mathrm{Cu}_{8} \mathrm{X}_{8}$ clusters $(\mathrm{X}=\mathrm{Cl}, \mathrm{Br}$, I; Chart 1) exist but are scarce. Indeed, only four cases are noted: a staircase octamer linked by a tetraphosphine ligand (0D), ${ }^{63}$ a corner-shared fused cubanes driven by the small N-N bite distance of dimethyl-2,2'-biimidazole (1D), ${ }^{64}$ an expanded hexagonal prism (i.e. double sideshared fused cubanes, 2D) ${ }^{65}$ and dicoordinated hexagonal prism (3D) ${ }^{66}$ No luminescence data have been reported for these species. Using these observations, one can anticipate that an 
emissive $\mathrm{CP}$ of $2 \mathrm{D}$ or 3D dimensionality and side-shared fused cubanes used as SBUs can be formed when $\mathrm{CuI}$ reacts with a dithioether sharing a certain structural similarity with DABCO.

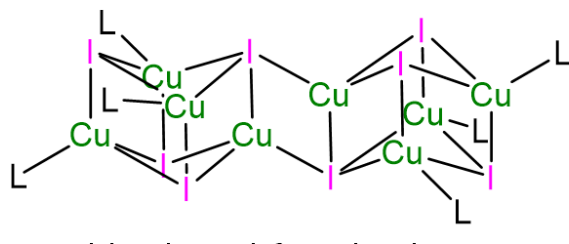

side-shared fused cubanes

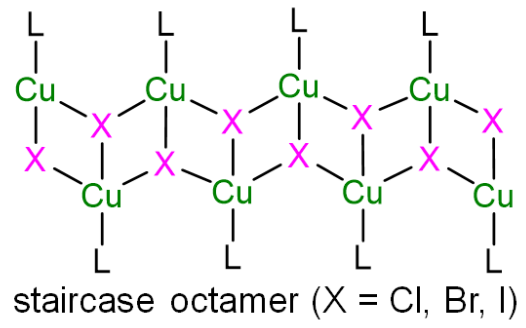

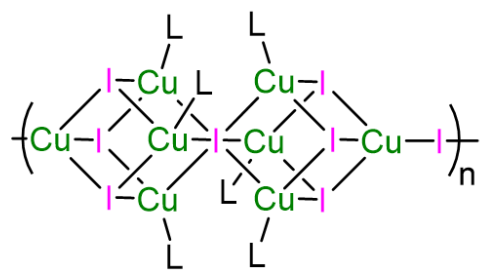

corner-shared fused cubanes

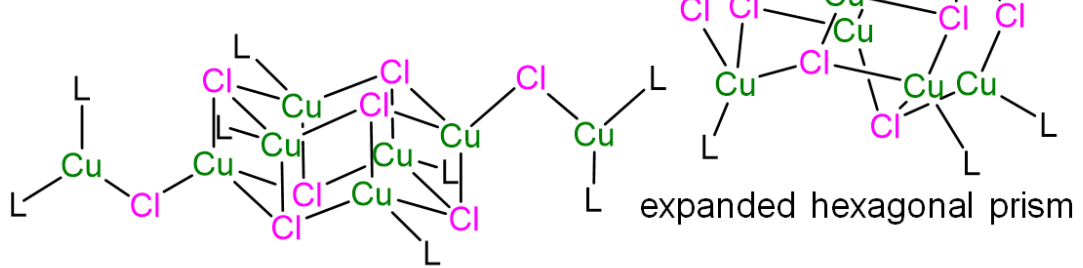

di-coordinated hexagonal prism

Chart 1. Structures of all encountered $\mathrm{Cu}_{8} \mathrm{X}_{8} \mathrm{~L}_{\mathrm{n}}$ clusters in 0-, 1-, 2-, and 3D materials $(\mathrm{X}=\mathrm{Cl}$, $\mathrm{Br}, \mathrm{I} ; \mathrm{n}=6$ (left), 8 (right); $\mathrm{L}=\mathrm{N}, \mathrm{O}, \mathrm{S}, \mathrm{P}$, or $\mathrm{C} \equiv \mathrm{C}$-donor).

We and others have recently investigated the coordination of the short-bite dithioether ligand $\mathrm{ArSCH}_{2} \mathrm{SAr}$ with $\mathrm{CuI}$ and isolated a large series of $1 \mathrm{D} \mathrm{CPs}$ or macrocyclic systems incorporating invariably $\mathrm{Cu}_{4} \mathrm{I}_{4}$ cubane cluster as SBUs, regardless of the substitution pattern of the Ar group. ${ }^{67}$, ${ }^{68}$ One possibility to further enhance the rigidity of a given dithioether is the use ligand having a cyclic framework such as 1,3-dithiane. Keller and Knaust reacted $\left[\mathrm{Cu}(\mathrm{MeCN})_{4}\right] \mathrm{BF}_{4}$ with this sixmembered thiaheterocycle and obtained four coordination networks depending on metal-to-ligand ratio and solvent conditions used. ${ }^{69}$ We report herein the coordination chemistry of the related ligand 2-methyl-1,3-dithiane, L1, combining both rigidity due to cyclic nature and enhanced basicity of the $S$-donor sites compared to $\mathrm{ArSCH}_{2} \mathrm{SAr}^{67,{ }^{68}}$ We now report that this choice of the ligand gives indeed rises to several CPs ranging from 1D-to-3D, whose architectures can be controlled by the proper reaction conditions. A rather important new feature is the observation of 
a strongly luminescent $\mathrm{CP}$ exhibiting an unprecedented $\mathrm{Cu}_{8} \mathrm{I}_{8}$ cluster as $\mathrm{SBU}$ built upon two sidefused open cubanes, whose photophysical properties have been thoroughly investigated. The nature of the emissive state has been addressed using DFT and TD-DFT computations. Attempts to convert the open dicubane SBUs into closed dicubanes where not successful, where only decomposition into $\gamma$-CuI was observed.

\section{EXPERIMENTAL SECTION}

Materials and Methods. Reactions were performed using Schlenk techniques. 2-methyl-1,3dithiane (98\%, Alfa Aesar), CuI (Fischer) and proprionitrile (ACROS) were purchased and used as received. Dry $\mathrm{CH}_{3} \mathrm{CN}$ was purified using a PureSolve MD5 system from Innovative Technology. The samples for powder XRD measurements were mixed with a small amount of paratone oil, cut to approximately $0.3 \times 0.3 \times 0.3 \mathrm{~mm}^{3}$, and placed on a sample holder mounted at $173.2 \mathrm{~K}$ on a Bruker APEX DUO X-ray diffractometer. Six correlated runs per sample with Phi Scan of 360 degrees and exposure times of $270 \mathrm{~s}$ were collected with the Cu micro-focus anode (1.54184 $\AA$ ) and the CCD APEX II detector at a $150 \mathrm{~mm}$ distance. These runs, from -12 to $-72^{\circ} 2 \theta$ and 6 to $36 \omega$, were then treated and integrated with the XRW2 Eval Bruker software to produce WAXD diffraction patterns from 2.5 to $82^{\circ} 2 \theta$. The patterns were treated with Diffrac.Eva version 2.0 from Bruker. The thermal analysis (TGA) traces were measured on a Perkin Elmer TGA 7 apparatus in the temperature range between 25 and $950{ }^{\circ} \mathrm{C}$ at a scanning rate of $10^{\circ} \mathrm{C} \cdot \mathrm{min}^{-1}$ under argon atmosphere. The differential scanning calorimetry (DSC) plots were measured on a DSC Q200 instrument equipped with a cooling system RCS 90 both from TA instrument at a scanning rate of $10^{\circ} \mathrm{C} \cdot \mathrm{min}^{-1}$. The IR spectra were recorded with a $2 \mathrm{~cm}^{-1}$ resolution on a Bruker vertex70 FTIR spectrometer using of a Platinum ATR accessory equipped with a diamond crystal. The FT-Raman spectra were recorded at $5 \mathrm{~cm}^{-1}$ resolution using a Bruker RFS 100/S spectrometer with the $1064 \mathrm{~nm}$ excitation and a light power equal to $250 \mathrm{~mW}$ equipped with a photomultiplier Ge-diode, cooled at liquid nitrogen temperature $(77 \mathrm{~K})$. The peak centered between 83 and $85 \mathrm{~cm}^{-1}$ is considered as residual artefact from the instrument and shouldn't be considered. The solid-state UV-visible spectra were recorded on a Varian Cary 300 Bio UV-Vis spectrophotometer at $298 \mathrm{~K}$ using raised-angle transmittance apparatus and a homemade $77 \mathrm{~K}$ sample-holder. Solid-State emission, excitation, lifetimes and CIE 1931 charts 
(chromaticity coordinates) were acquired on a phosphorimeter FLS980 from Edinburgh Instruments equipped with single monochromators. Samples were introduced in a capillary and spectra obtained were corrected for instrument response. The emission lifetime measurements were performed using a "flash" pulsed lamp. Lifetimes values were obtained using a time correlated single photon counting (TCSPC) system and data were treated from both deconvolution of multi-exponential analysis and exponential series method. Solid State emission quantum yields were recorded using a Quanta- $\varphi$ F-3029 integration sphere from Horiba plugged into a Horiba Fluorolog III.

DFT calculations. All density functional theory (DFT) and time-dependent (TDDFT) calculations were performed with Gaussian $09^{70}$ at the Université de Sherbrooke with the Mammouth supercomputer supported by Le Réseau Québécois De Calculs Hautes Performances. The DFT calculations ${ }^{71-80}$ were carried out using the B3LYP method. A 6-31g* basis set was used for $\mathrm{C}, \mathrm{H}$ and $\mathrm{S}$ atoms. ${ }^{81-87} \mathrm{VDZ}$ (valence double $\zeta$ ) with SBKJC effective core potentials were used for all $\mathrm{Cu}$ and I. The TDDFT analysis were carried out directly on *.cif files without any optimisation.

X-ray crystallography. Single crystals of CP1, CP2 and CP3 were mounted on a Bruker D8 Venture four-circle diffractometer equipped with a nitrogen jet stream low temperature system (Oxford Cryosystems). The X-ray source was graphite monochromated Mo-K $\alpha$ radiation $(\lambda=$ $0.71073 \AA$ ) from a microfocus sealed tube $\mathrm{I} \mu \mathrm{S}$ by Inocatec. Data collections have been carried out at $100 \mathrm{~K}$ in the case of $\mathbf{C P 1}$ and $\mathbf{C P 2}$, in the case of $\mathbf{C P 3}$ data were collected at five different temperatures: $100,150,200,250$ and $300 \mathrm{~K}$, using the same crystal. The lattice parameters were obtained by least-squares fit to the optimized setting angles of the entire set of collected reflections. Intensity data were recorded as $\phi$ and $\omega$ scans with $\kappa$ offsets. No significant intensity decay or temperature drift was observed during data collections. Data were reduced by using SAINT v8.37A (Bruker, 2015) software and absorption correction was carried out by SADABS2016/2 (Bruker, 2016). The structure was solved using SHELXT (Sheldrick, 2015) with intrinsic phasing. Refinements were carried out by full-matrix least-squares on F2 using SHELXL program (Sheldrick, 2015) on the complete set of reflections.2 All non-hydrogen atoms were refined with anisotropic thermal parameters, whereas the $\mathrm{H}$ atoms were treated in a riding mode. X-ray analysis at 350 and $400 \mathrm{~K}$. A prism-like crystal of CP3 of approximate dimensions $0.116 \times 0.163$ $\mathrm{x} 0.180 \mathrm{~mm}^{3}$, was mounted for the X-ray analysis. The X-ray intensity data were measured on a 
Bruker Kappa APEX II DUO CCD system equipped with a TRIUMPH curved-crystal monochromator and a Mo fine-focus tube $(\lambda=0.71073 \AA)$. The total exposure time was 4.41 hr. The frames were integrated with the Bruker SAINT software package using a narrow-frame algorithm. The integration of the data using a mono-clinic unit cell yielded a total of 24264 reflections to a maximum $\theta$ angle of $26.79^{\circ}(0.79 \AA$ resolution), of which 4947 were independent (average redundancy 4.905 , completeness $=99.1 \%, \mathrm{R}_{\text {int }}=9.49 \%, \mathrm{R}_{\text {sig }}=7.98 \%$ ) and $3317(67.05 \%)$ were greater than $2 \sigma\left(\mathrm{F}^{2}\right)$. The final cell constants of $\underline{a}=11.6059(10) \AA$, $\underline{\mathrm{b}}=12.8056(11) \AA, \underline{\mathrm{c}}=15.7394(13) \AA, \beta=90.893(4)^{\circ}$, volume $=2338.9(3) \AA^{3}$, are based upon the refinement of the XYZ-centroids of 9974 reflections above $20 \sigma(\mathrm{I})$ with $4.735^{\circ}<2 \theta$ $<52.90^{\circ}$. Data were corrected for absorption effects using the multi-scan method (SADABS). The ratio of minimum to maximum apparent transmission was 0.541 . The calculated minimum and maximum transmission coefficients (based on crystal size) are 0.2880 and 0.4140 . The structure was solved and refined using the Bruker SHELXTL Software Package, using the space group P1 21/c 1, with $\mathrm{Z}=4$ for the formula unit, $\mathrm{C}_{10} \mathrm{H}_{20} \mathrm{Cu}_{4} \mathrm{I}_{4} \mathrm{~S}_{4}$. The final anisotropic full-matrix least-squares refinement on $\mathrm{F}^{2}$ with 202 variables converged at $\mathrm{R} 1=6.75 \%$, for the observed data and wR2 $=20.94 \%$ for all data. The X-ray data are placed in Tables S1 and S2.

Synthesis of CP1: To a solution of 2-methyl-1,3-dithiane $(0.3 \mathrm{~mL}, 2.5 \mathrm{mmol})$ in $5 \mathrm{~mL}$ of acetonitrile was added an acetonitrile solution of $\mathrm{CuI}(345 \mathrm{mg}, 1.81 \mathrm{mmol})(40 \mathrm{~mL})$. A white precipitate appeared within $5 \mathrm{~min}$. The mixture was stirred for $3 \mathrm{~h}$ to complete the reaction. The precipitate was filtered, washed with $2 \times 30 \mathrm{~mL}$ acetonitrile and dried to give $\mathbf{C P 1}$ as a white solid (363 mg, 62\%). IR (ATR): 2952 w, 2935 w, 2904 w, 1449 w, 1422 s, 1405 m, 1375 w, 1178 w, 1162 w, 1122 m, 1074 m, 1047 m, 998 w, 904 s, 873 m, 707 m, 663 s. Anal. Calc for $\mathrm{C}_{5} \mathrm{H}_{10} \mathrm{CuIS}_{2}$ (324.69): \%C 18.49, \%H 3.10, \%S 19.75; found \%C 19.77, \%H 3.30, \%S 20.55.

Synthesis of CP2: To an acetonitrile solution of CuI (345 mg, $1.81 \mathrm{mmol})$ (40 mL) was added neat 2-methyl-1,3-dithiane $(0.3 \mathrm{~mL}, 2.5 \mathrm{mmol})$. A white precipitate appeared within $5 \mathrm{~min}$. The mixture was stirred for $3 \mathrm{~h}$ to complete the reaction. The precipitate was filtered, washed with 2 $\times 30 \mathrm{~mL}$ acetonitrile and dried to give $\mathbf{C P 2}$ as a white solid (372 mg, 63\%) IR (ATR):2935 w, 2902 w, 1448 w, 1421 s, 1407 s, 1368 m, 1232 s, 1170 m, 1115 m, 1055 s, 907 s, 870 m, 819 m, $712 \mathrm{~m}, 669 \mathrm{~s}, 490 \mathrm{~m}$. Anal. Calc for $\mathrm{C}_{5} \mathrm{H}_{10} \mathrm{CuIS}_{2}$ (324.69): \%C 18.49, \%H 3.10, \%S 19.75; found $\% \mathrm{C} 19.02, \% \mathrm{H} 3.24, \% \mathrm{~S} 20.65$. 
Synthesis of CP3: To solution of CuI in slight excess ( $478 \mathrm{mg}, 2.5 \mathrm{mmol})$ in proprionitrile (50 $\mathrm{mL}$ ) was added $\mathbf{L 1}(134 \mathrm{mg}=0.12 \mathrm{~mL}, 1.0 \mathrm{mmol})$. A white precipitate was formed within 5 min. The suspension was stirred for additional $30 \mathrm{~min}$ and heated under reflux for $3 \mathrm{~h}$ to dissolve most of the precipitate. After, the solution was allowed to cool slowly to room temperature, an homogenous microcystalline material precipitated. During the course of several days, crystals suitable for X-ray analysis appeared as small blocks. An addition, a crop of CP3 was collected after filtering off the solid and while storing the EtCN solution in a refridgerator. Overall yield: 434 mg, 84\%. IR (ATR):2954 w, 2898 w, 2878 w, 1439 w, 1417 s, 1404 s, 1371 m, 1232 s, 1195 m, 1172 m, 1055 s, 905 s, 865 m, 815 m, 712 m, 484 m. Anal. Calc for $\mathrm{C}_{10} \mathrm{H}_{20} \mathrm{Cu}_{4} \mathrm{I}_{4} \mathrm{~S}_{4}(1030.26)$ : $\% \mathrm{C} 11.66, \% \mathrm{H} 1.96, \% \mathrm{~S} 12.45$; found $\% \mathrm{C} 11.96, \% \mathrm{H} 2.05, \% \mathrm{~S} 12.85$.

\section{RESULTS AND DISCUSSION}

First, $\mathbf{L 1}$ was reacted with one equimolar amount of $\mathrm{CuI}$ in $\mathrm{MeCN}$ solution. A quasi-quantitative precipitation of a colorless sparingly soluble white product readily occurred. The elemental analysis indicated a 1:1 Cu/L1 composition $\left[\left\{\mathrm{Cu}\left(\mu_{2}-\mathrm{I}\right)_{2} \mathrm{Cu}\right\}\left(\mu_{2}-\mathbf{L} \mathbf{1}\right)_{2}\right]_{n}$. Crystals suitable for X-ray diffraction analysis were obtained by dissolving a small amount of this white product in boiling propionitrile and then allowing the crystals to form slowly (Scheme 1). Unexpectedly, two types of crystals with different shapes were detected under a microscope. First, the major fraction consisted of needle-shaped colorless crystals and crystallography analyses revealed the presence of simple 1D ribbons $\left[\left\{\mathrm{Cu}\left(\mu_{2}-\mathrm{I}\right)_{2} \mathrm{Cu}\right\}\left(\mu_{2}-\mathbf{L 1}\right)_{2}\right]_{n} \mathbf{C P 1}$, in which centrosymmetric dinuclear $\mathrm{Cu}\left(\mu_{2}-\right.$ I $)_{2} \mathrm{Cu}$ rhomboids are spanned by linking $\mathbf{L 1}$ ligands (Figure 1). Although this structural motif is quite common and has been encountered for other 1D CPs described by our groups such as $\left[\left\{\mathrm{Cu}\left(\mu_{2}-\mathrm{I}\right)_{2} \mathrm{Cu}\right\}_{2}\left\{\mu-\mathrm{PhS}\left(\mathrm{CH}_{2}\right)_{5} \mathrm{SPh}\right\}_{2}\right]_{n}$, the very loose $\mathrm{Cu} \cdots \mathrm{Cu}$ contact of $\mathbf{C P 1}$ reaching $3.367 \AA$ deserves some comments. This extreme value exceeds even the long $\mathrm{Cu} \cdots \mathrm{Cu}$ separation of 3.18 $\AA$ A reported for the 2D material $\left[\left(\mathrm{Cu}_{2} \mathrm{I}_{2}\right)(\mathrm{dtpcp})_{2} \bullet\right.$ thf $\left.)\right]_{\mathrm{n}}(\mathrm{dtpcp}=2,11$-dithia[3.3]paracyclophane $){ }^{88}$ Concurrently, there are examples with short $\mathrm{Cu}-\mathrm{Cu}$ bonds given by a dithioether-functionalized tetrathiafulvalene $\mathrm{Cu}(\mathrm{I})$ complex with a separation of $2.65 \AA$ and a $1 \mathrm{D}$ polymer $\left[\left(\mathrm{Me}_{2} \mathrm{~S}\right)_{2}\left\{\mathrm{Cu}_{2}\left(\mu_{2}\right.\right.\right.$ $\left.\left.\mathrm{I}_{2}\right\}\right]_{\mathrm{n}}$, in which the metal centers within the rhomboid cluster are separated by $2.684(1) \AA{ }^{89,90} \mathrm{In}$ contrast to $\mathbf{C P 1}$, the $\left[\left\{\mathrm{Cu}\left(\mu_{2}-\mathrm{I}\right)_{2} \mathrm{Cu}\right\}\right.$ SBUs in the 1D CP $\left[\left\{\mathrm{Cu}\left(\mu_{2}-\mathrm{I}\right)_{2} \mathrm{Cu}\right\}(1,2 \text {-dithiane })_{2}\right]_{n}$ adopt an horizontally aligned orientation, with a quite short $\mathrm{Cu}-\mathrm{Cu}$ distance of 2.6843(18) $\AA^{91} \mathrm{~A}$ 
representative example for a CP exhibiting medium range $\mathrm{Cu} \cdots \mathrm{Cu}$ separation $(2.8058(11) \AA$ ) is the 1D CP $\left[\left\{\mathrm{Cu}\left(\mu_{2}-\mathrm{I}\right)_{2} \mathrm{Cu}\right\}_{2}\left\{\mu-\mathrm{PhS}\left(\mathrm{CH}_{2}\right)_{5} \mathrm{SPh}\right\}_{2}\right]_{n}{ }^{92}$ This broad range of $\mathrm{Cu} \cdots \mathrm{Cu}$ separations underpins the structural flexibility of the $\mathrm{Cu}\left(\mu_{2}-\mathrm{I}\right)_{2} \mathrm{Cu}$ motif.

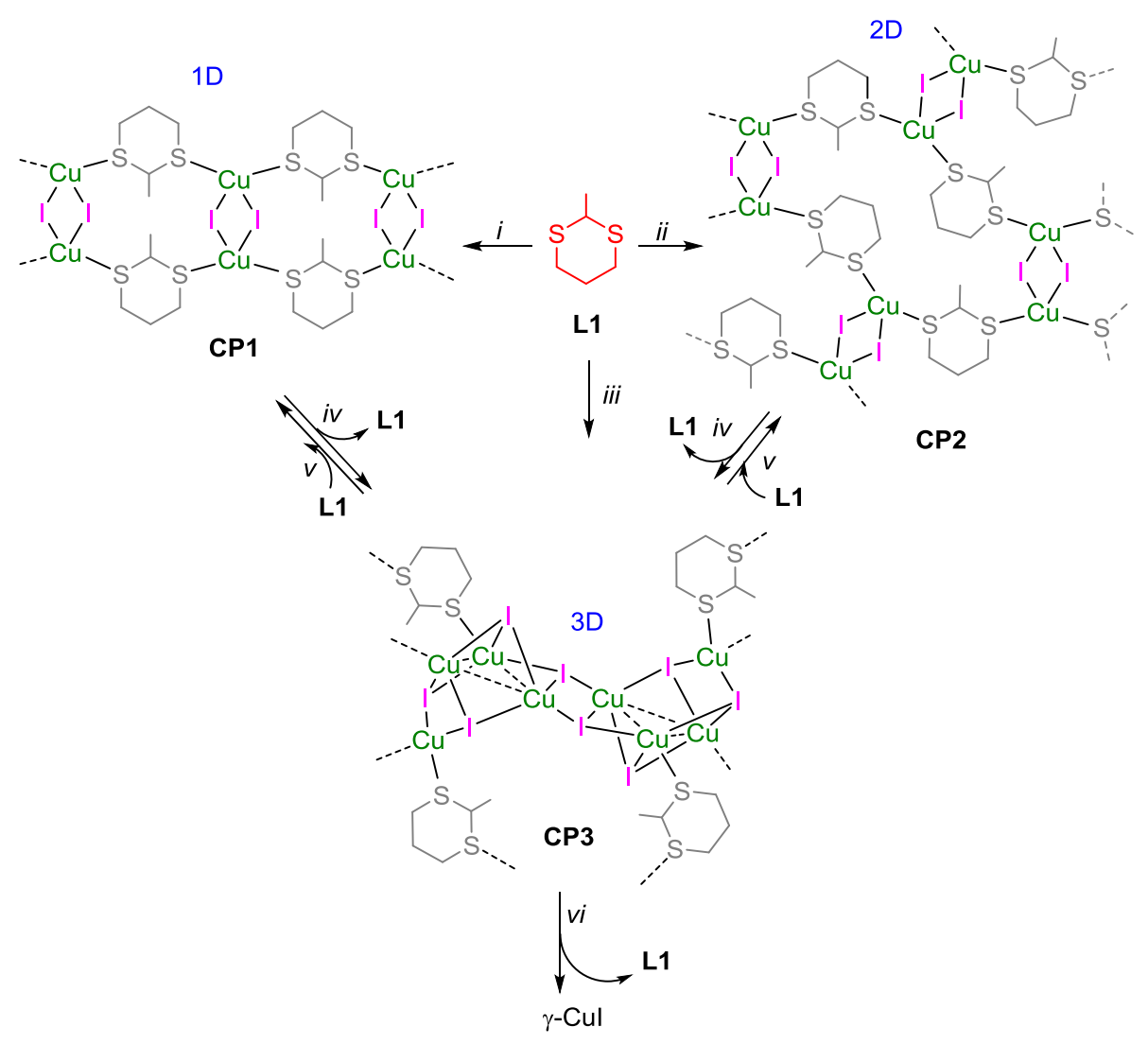

Scheme 1. Synthesis of CP1 to CP3: i) 1:1 CuI in L1/MeCN RT, ii) 1:1 L1 in CuI/MeCN RT, iii) 2:1 CuI in L1/EtCN reflux, iv) PrCN, reflux, v) 1Eq. L1 vi) $\mathrm{T}=170{ }^{\circ} \mathrm{C}$.

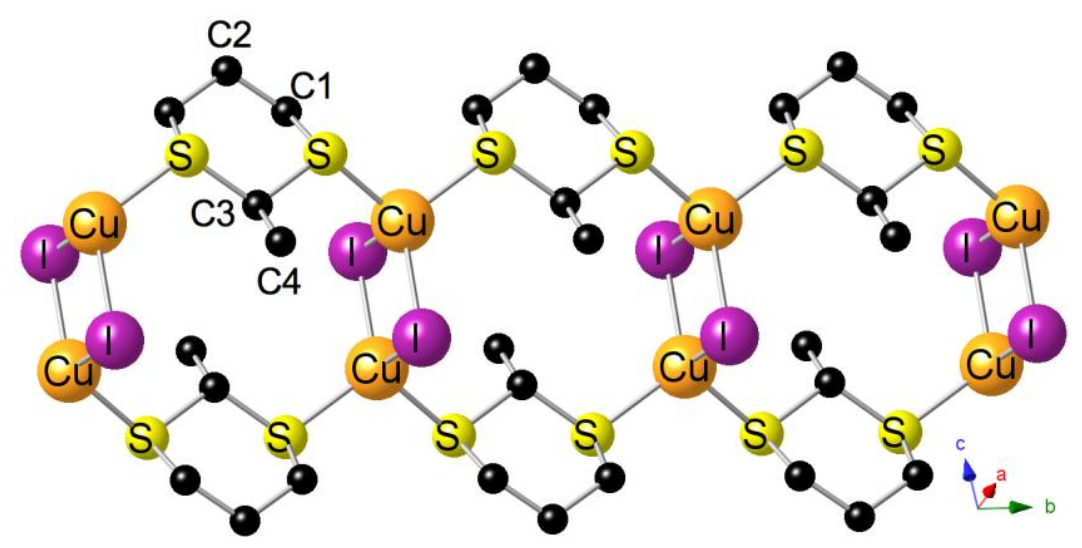

Figure 1. View of a segment of the $1 \mathrm{D}$ ribbon of $\left[\left\{\mathrm{Cu}\left(\mu_{2}-\mathrm{I}\right)_{2} \mathrm{Cu}\right\}\left(\left(\mu_{2}-\mathbf{L 1}\right)_{2}\right]_{\mathrm{n}} \mathbf{C P 1}\right.$ running along the $b$ axis. Selected bond lengths $(\AA)$ and angles $\left({ }^{\circ}\right): \mathrm{Cu} \cdots \mathrm{Cu} \# 3.367, \mathrm{Cu}-\mathrm{I} 2.6061(3), \mathrm{Cu}-\mathrm{I} \#$ 
2.6834(4), Cu\#-I 2.6835(4), Cu-S 2.3316(4), Cu-I-Cu\# 79.042(10), I-Cu-I\# 100.958(10), S$\mathrm{Cu}-\mathrm{I}$ 117.461(12), S-Cu-I\# 108.487(13), S-Cu-S\# 103.58(2). Symmetry transformations used to generate equivalent atoms: \#1 1-x, -y, 1-z \#2+x, -y, $+\mathrm{z} \quad \# 3+\mathrm{x},-\mathrm{y},+\mathrm{z}$.

CP2 is prepared by adding $\mathbf{L} 1$ to an acetonitrile solution of $\mathrm{CuI}$ in $1: 1 \mathrm{Cu} / \mathbf{L} 1$ ratio at room temperature. Crystals were obtained from slow evaporation of a acetonitrile solution. X-ray analysis the crystals stemming from the minor fraction revealed that $\mathbf{C P 2}$ is an isomeric form of CP1, which differ by the connectivity of the sulfur atoms with the $\mathrm{Cu}$ atoms, giving rise to a $2 \mathrm{D}$ network (Figure 2).

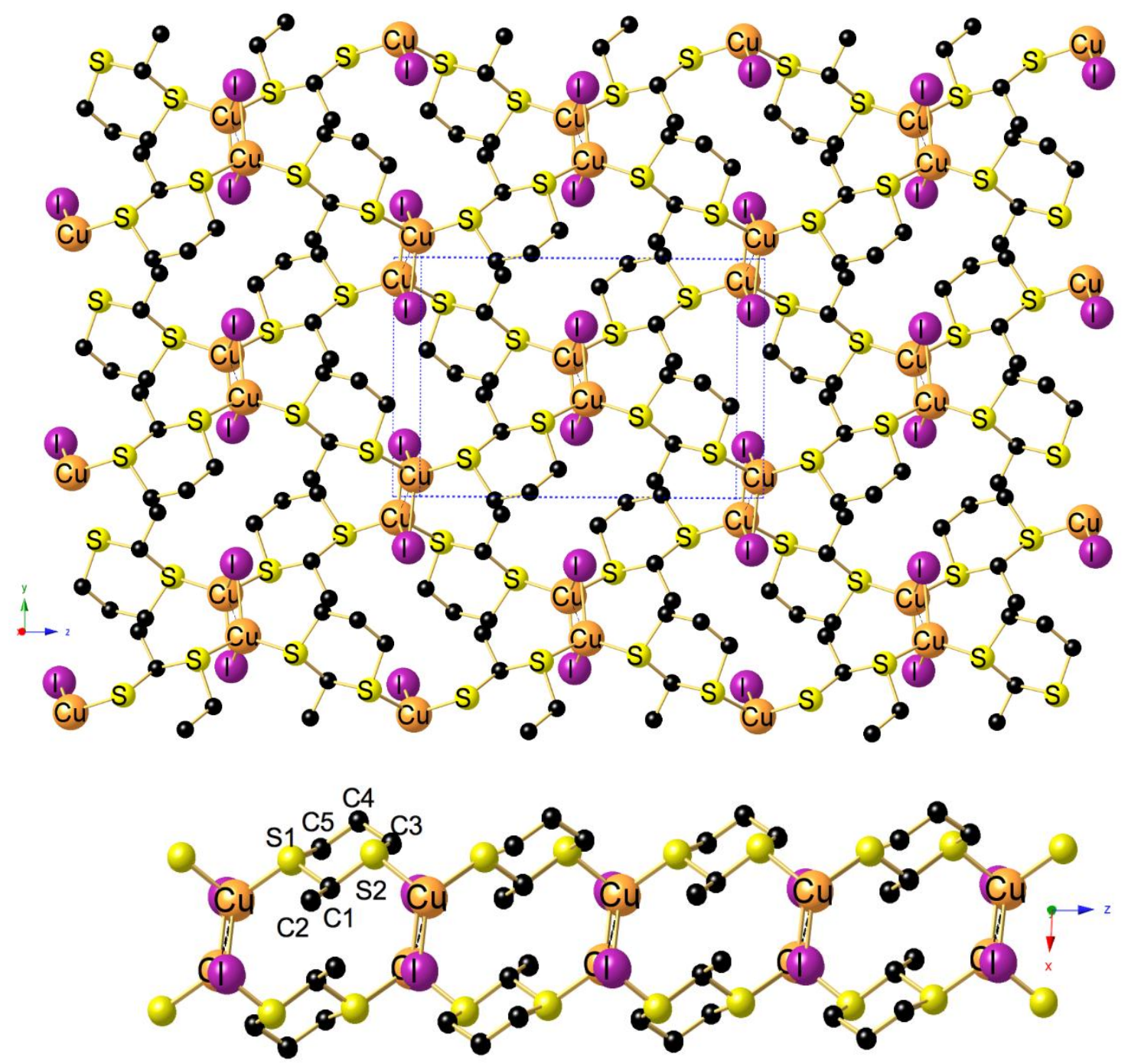

Figure 2. (Top) View on the $y, z$ plane of the 2D network of $\left[\left\{\mathrm{Cu}\left(\mu_{2}-\mathrm{I}\right)_{2} \mathrm{Cu}\right\}\left(\mu_{2}-\mathbf{L 2}\right)_{2}\right]_{n} \mathbf{C P 2}$. Selected bond lengths $(\AA)$ and angles $\left({ }^{\circ}\right)$ : $\mathrm{Cu} \cdots \mathrm{Cu} \#$ 2.7664(6), $\mathrm{Cu}-\mathrm{I}$ 2.6162(5), $\mathrm{Cu}-\mathrm{I} \#$ 
2.6348(4), Cu\#-I 2.6348(4), Cu-S1 2.3195(6), Cu-S2 2.3606(6), I-Cu-I\# 116.418(11), I-Cu$\mathrm{Cu} \#$ 58.537(14), I\#-Cu-Cu\# 57.882(11), S1-Cu-I 118.275(18), S1-Cu-I\# 108.194(17), S1-CuS2 98.51(2), S2-Cu-I 107.993(18), S2-Cu-I\# 105.133(17) Symmetry transformations used to generate equivalent atoms: \#1 1-x,1-y,1-z \#2+x,1/2-y,-1/2+z \#3+x,1/2-y,1/2+z. (Bottom) View down the $y$ axis on a segment of a layer of $\mathbf{C P 2}$ running along the $z$ axis.

In this case, the SBUs are again constituted of dinuclear $\mathrm{Cu}\left(\left(\mu_{2}-\mathrm{I}\right)_{2} \mathrm{Cu}\right.$ rhomboids, which are spanned by both sulfur atoms of $\mathbf{L 1}$, thus forming 20 -membered macrocycles in the layer. But in contrast to the 1D isomer CP1 possessing just one type of crystallographically equivalent S atoms, the $\mathrm{Cu}$ atoms of the $2 \mathrm{D}$ isomer are ligated datively by two crystallographically different $\mathrm{S}$ atoms with $\mathrm{Cu}-\mathrm{S} 1$ and $\mathrm{Cu}-\mathrm{S} 2$ bond lengths of 2.3195(6) and 2.3606(6) $\AA$, respectively. Another marked difference is the much closer $\mathrm{Cu} \cdots \mathrm{Cu}$ contact of 2.7664(6) $\AA$, indicating at least a weak intermetallic interaction. This network topology is quite reminiscent to that of $2 \mathrm{D}$ material [ $\left.\left\{\mathrm{Cu}\left(\mu_{2}-\mathrm{I}\right)_{2} \mathrm{Cu}\right\}\left(\mu_{2}-1,3 \text {-dithiolane }\right)_{2}\right]_{n}$ resulting from the coordination of 1,3-dithiolane to $\mathrm{CuI}$, and featuring a $\mathrm{Cu} \cdots \mathrm{Cu}$ distances of $2.8743(5) \AA$ at $100 \mathrm{~K} .{ }^{39}$ Other similar $2 \mathrm{D}$ grids have previously been obtained from the reaction of $\mathrm{CuI}$ with the open-chain dithioethers 1,3bis(phenylthio)propane and 1,3-bis(phenylthio)ethane respectively yielding $\left[\left\{\mathrm{Cu}\left(\mu_{2}-\mathrm{I}\right)_{2} \mathrm{Cu}\right\}_{2}\{\mu-\right.$ $\left.\left.\mathrm{PhS}\left(\mathrm{CH}_{2}\right)_{3} \mathrm{SPh}\right\}_{2}\right]_{n}$ and $\left[\left\{\mathrm{Cu}\left(\mu_{2}-\mathrm{I}\right)_{2} \mathrm{Cu}\right\}_{2}\left\{\mu-\mathrm{PhS}\left(\mathrm{CH}_{2}\right)_{2} \mathrm{SPh}\right\}_{2}\right]_{n} .{ }^{92,93}$

CP1 and $\mathbf{C P 2}$ can be therefore considered as topological isomers of formula $\left[\left\{\mathrm{Cu}_{2}\left(\mu_{2}-\mathrm{I}\right)_{2}\right\}\left(\mu_{2^{-}}\right.\right.$ L1) $\left.{ }_{2}\right]_{\mathrm{n}}$ having the same 1:1 metal-to-ligand ratio, but different dimensionalities. Another example of topological isomerism in coordination polymers has been described by Champness, Hanton et $a l$. This group has shown that three $\mathrm{CPs}$ of composition $\left[(\mathrm{CuI})_{2}(\mathrm{bpds})\right]_{\mathrm{n}}$ are formed between $\mathrm{CuI}$ and bpds [bpds = bis(4-pyridyl)disulfide] depending upon the solvent used in crystallization and concludes that there are only minor energy differences in the formation. ${ }^{94}$

In order to control in a more selective manner the dimensionality of the materials, we added a $\mathrm{MeCN}$ solution of $\mathrm{CuI}$ to a $\mathrm{MeCN}$ solution of $\mathbf{L 1}$. This procedure yielded $\mathbf{C P 1}$ in high purity as checked by PXRD (Figure 3). Inversely, CP2 could be isolated as principal isomer by dropping L1 at ambient temperature to a solution of $\mathrm{CuI}$ in $\mathrm{MeCN}$ (Scheme 1). Again, the purity of the phase could be ascertained by comparison of the calculated and experimental PXRD spectra with those obtained from single X-ray analysis (Figure 3). 
The outcome of the reaction is furthermore impacted by the metal-to-ligand ratio. Addition of neat $\mathbf{L 1}$ into an EtCN solution containing 2 equiv. of $\mathrm{CuI}$ led to the 3D $\mathrm{CP}\left[\left\{\mathrm{Cu}_{8}\left(\mu_{3}-\mathrm{I}\right)_{8}\right\}\left(\mu_{2^{-}}\right.\right.$ L1 $\left.)_{4}\right]_{\mathrm{n}}$, CP3. This yellowish air-stable luminescent material featuring octanuclear $\mathrm{Cu}_{8} \mathrm{I}_{8}$ clusters as SBUs (based on X-ray crystallography below) was formed as sole product, for which the homogeneity of the phase was ascertained by PXRD measurements (Fig. S3 SI).
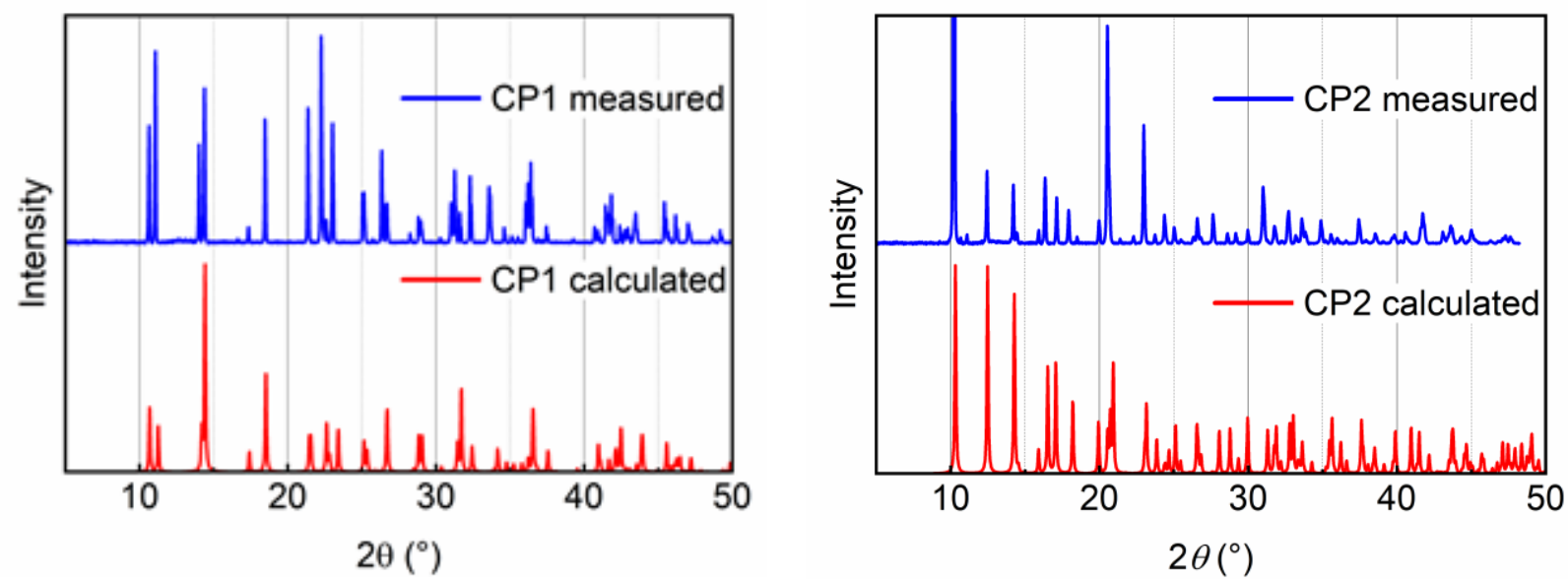

Figure 3. Comparison of experimental (red) and calculated (blue) PXRD patterns for CP1 and CP2.

The X-ray data revealed that CP3 exhibits an unprecedented motif; a side shared fused open dicubane $\mathrm{Cu}_{8} \mathrm{I}_{8} \mathrm{~L}_{8}$. This cluster differs from its homologous closed dicubane by $n$ the number of ligands binding the $\mathrm{Cu}_{8} \mathrm{I}_{8}$ clusters in $\mathrm{Cu}_{8} \mathrm{X}_{8} \mathrm{~L}_{\mathrm{n}}$. The centrosymmetric cluster core $\left(\mathrm{C}_{i}\right.$ point group) shown in Figure 4 consists of two $\mathrm{Cu} 1-\mathrm{Cu} 3-\mathrm{Cu} 4$ triangles with a mean $d(\mathrm{Cu}-\mathrm{Cu})$ of 2.7069(4) $\AA$ ), which is below the sum of the Van der Waals radii of two $\mathrm{Cu}$ atoms (2.8 $\AA$ ). Each triangle is $\mu_{3}$-capped by an I4 ligand. The fourth $\mathrm{Cu} 2$ atom is linked to $\mathrm{Cu} 1$ through the $\mu_{3}$-bridging $\mathrm{I} 1$ and I2 atoms with $\mathrm{Cu} \cdots \mathrm{Cu}$ distance of 2.9184(4) $\AA$. This motif may thus be described as a derivative of the widespread closed $\mathrm{Cu}_{4} \mathrm{I}_{4}$ cubane, ${ }^{38,39,60-62,67,68,95-97}$ in which two $\mathrm{Cu}-\mathrm{Cu}$ bonds (per cubane) have been disconnected. 

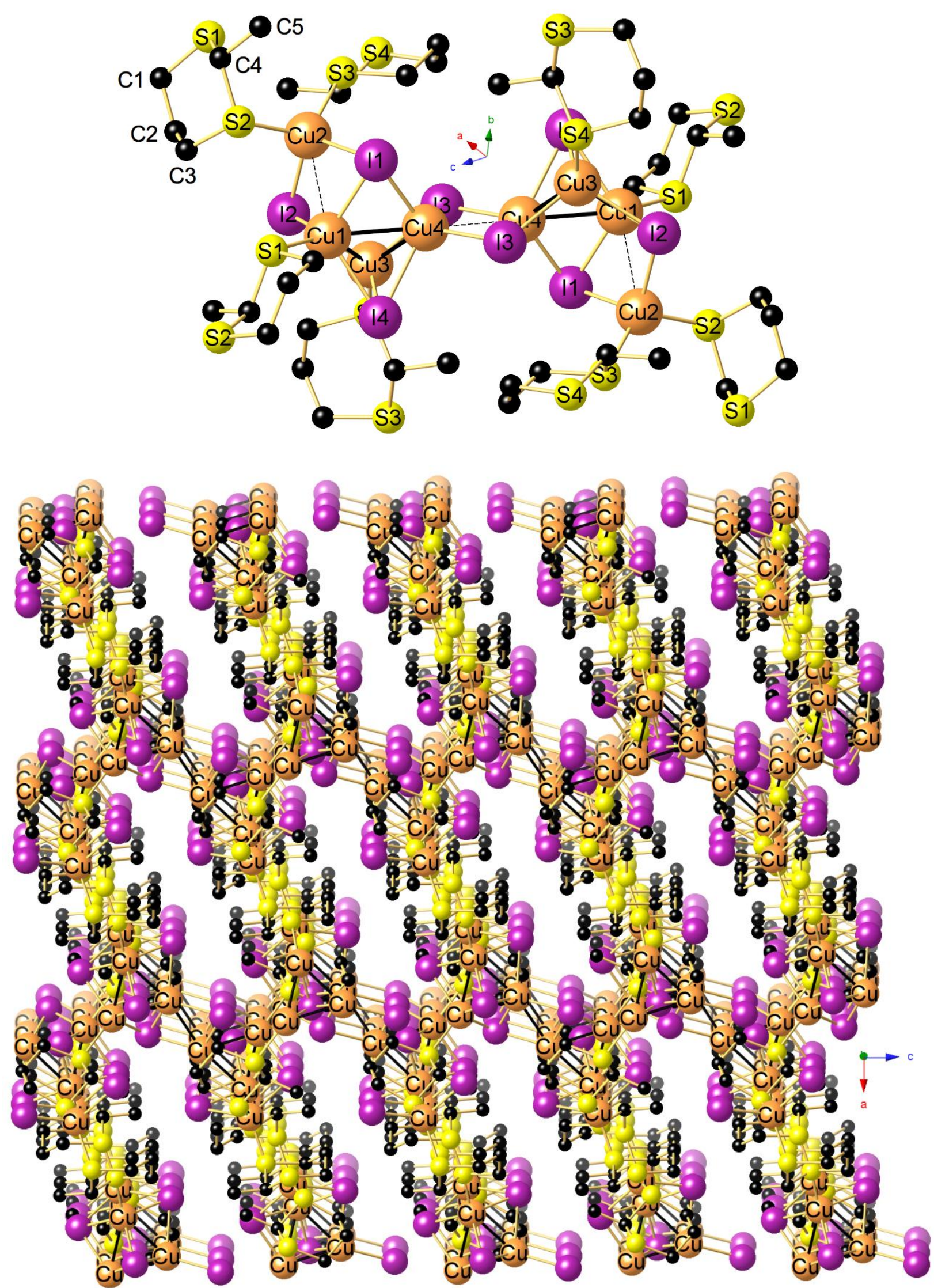
Figure 4. (Top) View of the $\mathrm{Cu}_{8} \mathrm{I}_{8} \mathrm{SBU}$ with its ligated L1's. Hydrogen atoms are omitted for clarity. Selected bond lengths $(\AA)$ and angles $\left(^{\circ}\right)$ at $100 \mathrm{~K}: \mathrm{Cu} 1-\mathrm{I} 42.6832(4), \mathrm{Cu} 1-\mathrm{I} 12.6445(5)$, Cu1-S1 2.3232(6), Cu2-S2 2.3010(6), Cu2-S3 2.3098(6), Cu3-S4 2.3117(6), Cu4-I3 2.6579(5), S1-S2 3.0263(7), S3-S4 2.9996(7); Cu4-I3-Cu4 67.245(13), S2-Cu2-S3 119.435(17), I3-Cu3I2 108.356(14), Cu1-I1-Cu4-61.654(11), Cu2-I2-Cu1 66.697(13), S1-C\#-S2 112.59(9), S3C\#-S4 110.80(9). Symmetry transformations used to generate equivalent atoms: $\# 1-1+\mathrm{x},+\mathrm{y},+\mathrm{z}$ \#2 1-x,-1/2+y,3/2-z \#3 1-x,1-y,1-z \#4 1-x,1/2+y,3/2-z \#5 2-x,1-y,1-z \#6 1+x,+y,+z. (Bottom) Perspective view down the $b$ axis of the 3D network of CP3. A perspective view down the $c$ axis of the 3D network of CP3 is given in ESI (Fig. S1).

This tetranuclear subunit is linked with the second one through a $\mathrm{Cu} 4 \cdots \mathrm{Cu} 4$ interaction and two $\mu_{3}$-bridging I3 ligands. A study of the temperature dependence of the $\mathrm{Cu} \cdots \mathrm{Cu}$ distances from $100-400 \mathrm{~K}$ reveals that $\mathrm{Cu} 4 \cdots \mathrm{Cu} 4$ separation of $2.9239(5) \AA$ at $100 \mathrm{~K}$ lengthens considerably to $2.985(5) \AA$ at $400 \mathrm{~K}$ (Figure S2; Table S3). No phase transition occurs in this $300 \mathrm{~K}$ interval (monoclinic, P21/c), also implying that the cubanes remained opened upon cooling. Whereas the $\mathrm{Cu} 1$ and $\mathrm{Cu} 3$ atoms are ligated by one $\mathrm{S}$ atom of $\mathbf{L 1}$, the $\mathrm{Cu} 2$ atom completes it coordination sphere with two dative $\mathrm{Cu}-\mathrm{S}$ bonds, the $\mathrm{Cu} 4$ center is surrounded by four $\mu_{3}$-iodo ligands exclusively. The assembly of the non-porous $3 \mathrm{D}$ network is secured by the coordination of the second $\mathrm{S}$ atom of the eight $\mathbf{L 1}$ ligands with adjacent $\mathrm{Cu}_{8} \mathrm{I}_{8}$ SBUs.

This structural difference between closed and open dicubane can also be deduced from the difference in the Raman response of $\mathbf{C P 3}$ compared to those for $\left[\mathrm{Cu}_{8} \mathrm{I}_{8}(\mathbf{L 2})_{3}(\mathrm{MeCN})_{2}\right]_{\mathrm{n}}(\mathbf{L 2}=p$ TolS $\left.\left(\mathrm{CH}_{2}\right)_{8} \mathrm{STol}-p\right)^{62}$ and $\mathrm{Cu}_{8} \mathrm{I}_{8}\left(\mathrm{~S}(\mathrm{i}-\mathrm{Pr})_{2}\right)_{6}{ }^{60}$ in the $50-500 \mathrm{~cm}^{-1}$ window. Indeed, the characteristic $v(\mathrm{CuI})$ region (i.e. $\left.80-150 \mathrm{~cm}^{-1}\right)^{98}$ exhibits a different signature (strong central peak) for CP3 compared to that (multiple shoulders) for $\left[\mathrm{Cu}_{8} \mathrm{I}_{8}(\mathbf{L 2})_{3}(\mathrm{MeCN})_{2}\right]_{\mathrm{n}}$ and $\mathrm{Cu}_{8} \mathrm{I}_{8}\left(\mathrm{~S}(\mathrm{i}-\mathrm{Pr})_{2}\right)_{6}($ Figures 5 and S9-S13). 


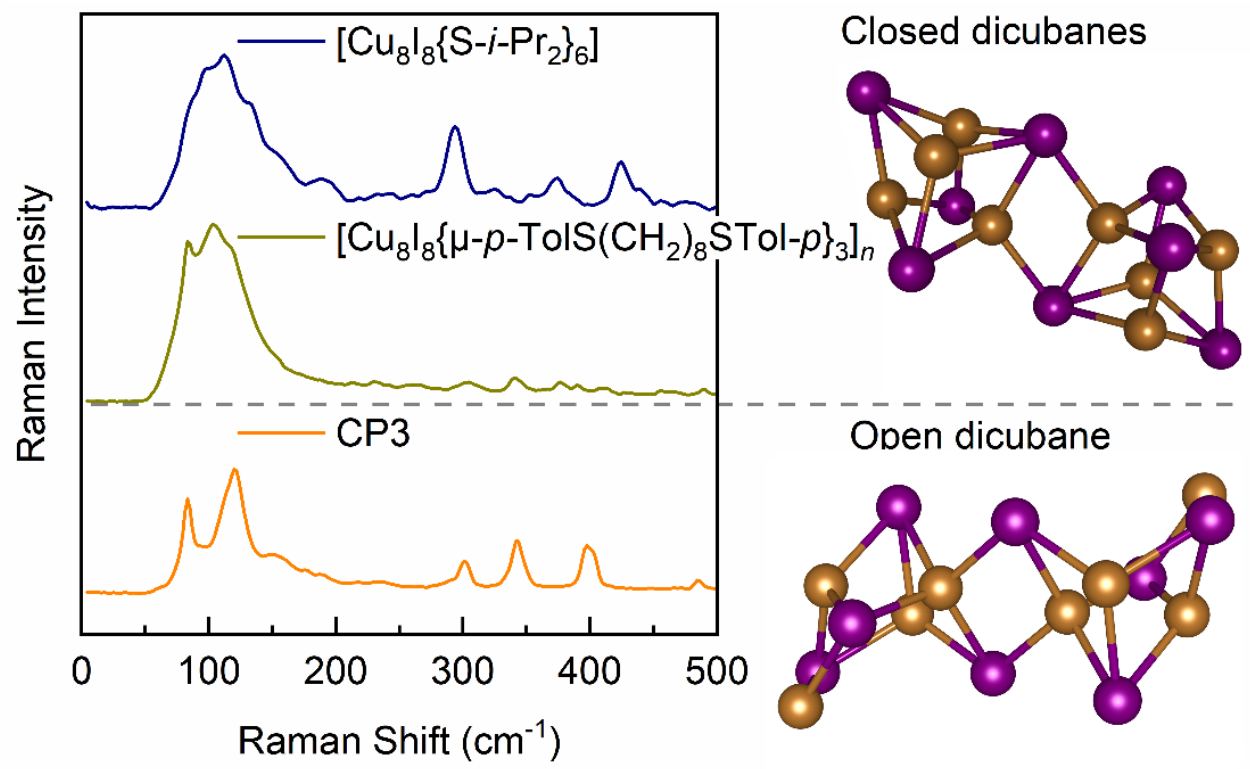

Figure 5. Solid-state FT-Raman spectra of closed and open dicubanes CPs in the 50-500 $\mathrm{cm}^{-1}$ region. The notch filter cutoff is $80 \mathrm{~cm}^{-1}$. All Raman data for the CPs are placed in Figures S9S13.

Interestingly, both CP1 and CP2 can be converted into CP3 in refluxing PrCN indicating that CP3 is the thermodynamic product (Scheme 1). The formation of CP3 from CP1 or CP2 can be explained as such: first, when the powder is dissolved, the coordination polymer breaks in many smaller soluble fragments, a common behavior to most CPs. ${ }^{99}$ Upon reflux in PrCN, L1 partially dissociates and consequently the $\mathrm{Cu} / \mathbf{L 1}$ ratio increases, resembling that of the synthesis conditions to prepare CP3. Upon standing, crystals of CP3 are reformed, as proven by PXRD analysis (Figure 6). Moreover, this reaction was shown to be reversible i.e. treatment of $\mathbf{C P 3}$ with 1 equiv. of $\mathbf{L 1}$ in refluxing EtCN led to a mixture of CP1 and CP2. Upon the re-dissolution of CP3, again the CP breaks into smaller fragments, and the re-introduction of $\mathbf{L} 1$ into a solution of CP3, CP1 (and CP2) are reformed when the crystals reformed. This report of this property is, to the best of our knowledge, also unprecedented. The CP transformation from $\left[\left\{\mathrm{Cu}_{2}\left(\mu_{2}-\mathrm{I}\right)_{2}\right\}\left(\mu_{2^{-}}\right.\right.$ L1 $\left.)_{2}\right]_{\mathrm{n}}$ to $\left[\left\{\mathrm{Cu}_{8}\left(\mu_{3}-\mathrm{I}\right)_{8}\right\}\left(\mu_{2}-\mathbf{L 1}\right)_{4}\right]_{\mathrm{n}}$ is not directed by porosity change of the lattice as there is no correlation between this parameter and the nature of the CP (CP1, 14.8; CP2, 19.7; CP3, $16.9 \%$; $100 \mathrm{~K}$ ). Instead, the cluster formation drives this process as the $\mathrm{Cu}_{8} \mathrm{I}_{8}$ unit exhibits more $\mathrm{Cu}-\mathrm{I}$ bonds and $\mathrm{Cu} \cdots \mathrm{Cu}$ interactions. 

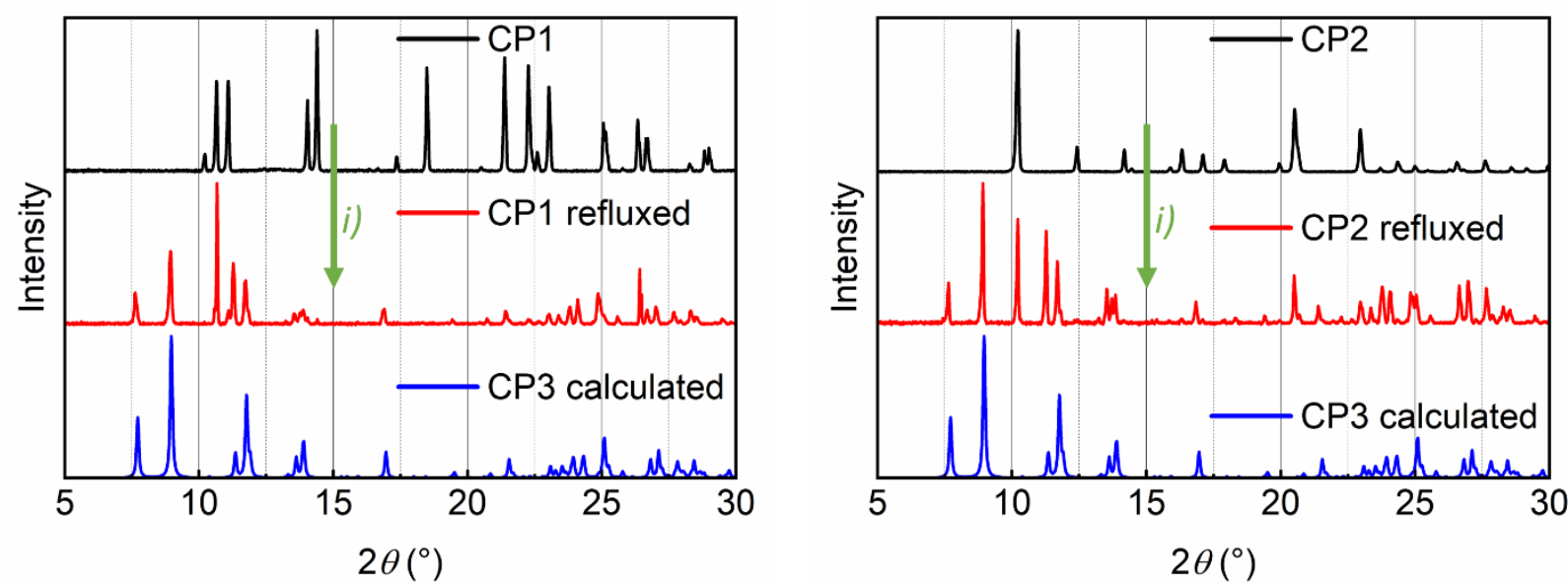

Figure 6. Powder X-ray diffraction patterns monitoring the transformation of CP1 to CP3 (left) and CP2 to CP3 (right). i) PrCN, reflux.

\section{Thermal stabilities}

The thermal stability of CP1, CP2 and CP3 was addressed by thermal gravimetric analysis (TGA) under argon up to $950^{\circ} \mathrm{C}$ (Figure 7; left). All CPs exhibit a similar thermal behavior where two main weight losses are readily depicted. This pattern is, in fact, typical for this type of $\mathrm{CP}{ }^{62}$ The first weight loss occurs between $170-270^{\circ} \mathrm{C}$. The corresponding DSC traces (Figure 7; right) revealed that, in this temperature range, three endothermic peaks are observed during the first scan, but all disappear during the next one, thus witnessing decomposition. The first weight loss corresponds to an irreversible process, that can be ascribed to a ligand loss. Based on this assumption, the experimental weight loss percent for topological isomer $\mathbf{C P 1}$ and $\mathbf{C P 2}$ (41 wt\%) matches perfectly with the theoretical value $(41 \mathrm{wt} \%)$ and is slightly higher for $\mathbf{C P 3}(28 \mathrm{wt} \% \mathrm{vs}$ $25 \mathrm{wt} \%$; Table 1). 

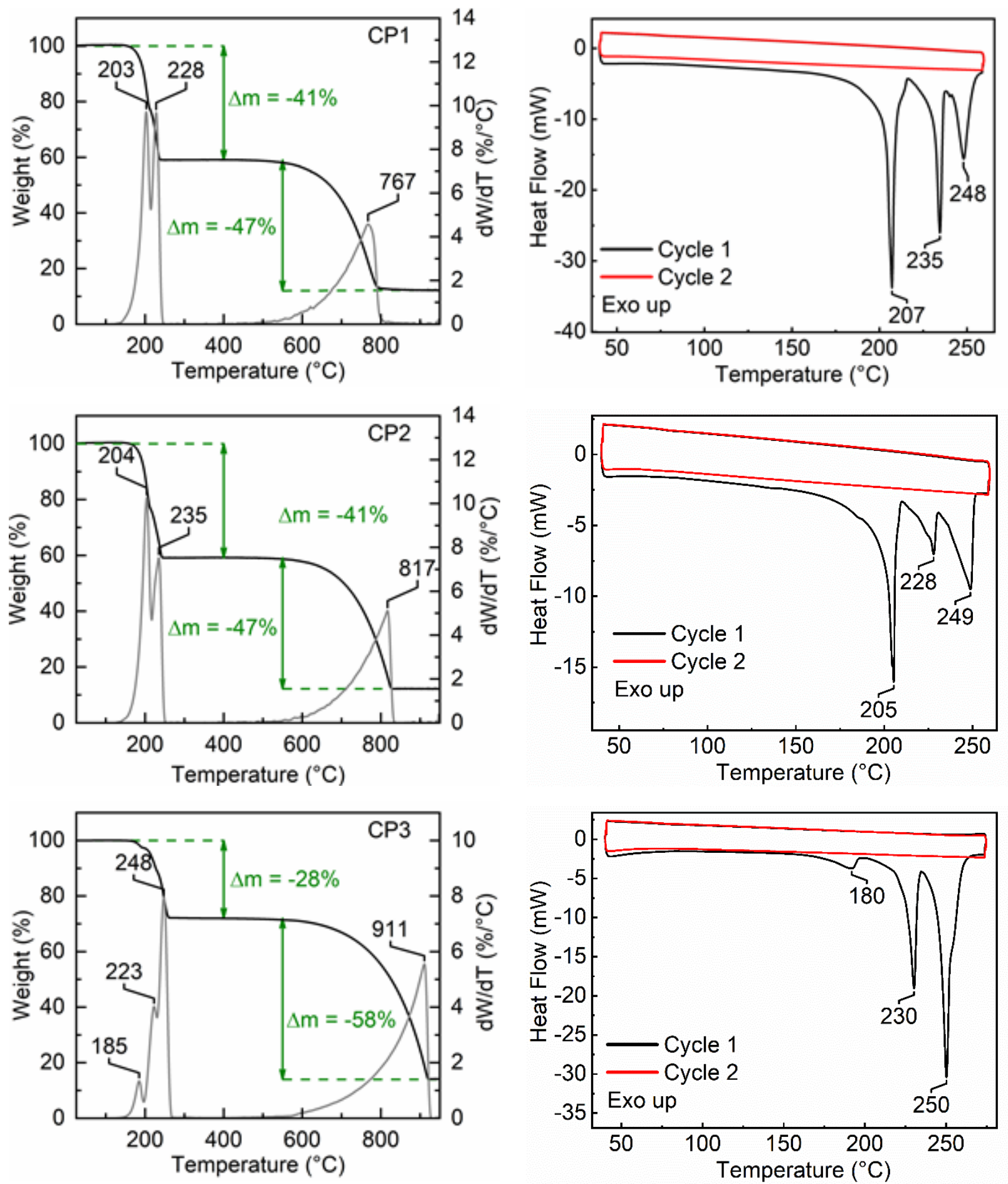

Figure 7: TGA traces (black; left) and its $1^{\text {st }}$ derivative (grey; left), and DSC traces (right) of CP1 (top) CP2 (middle) and CP3 (bottom) under $\operatorname{Ar}(\mathrm{g})$.

The thermal degradation temperatures that correspond to $5 \mathrm{wt} \%$ loss are $187^{\circ} \mathrm{C}$ and $189^{\circ} \mathrm{C}$ for CP1 and CP2 and $214{ }^{\circ} \mathrm{C}$ for $\mathbf{C P 3}$, which compared well to the values reported for other CPs 
incorporating $\mathrm{Cu}_{8} \mathrm{I}_{8}$ SBUs. ${ }^{62}$ This may be attributed to the high boiling point of the 2-methyl1,3-dithiane ligand $\left(\mathrm{bp}=224^{\circ} \mathrm{C}\right)$.

Table 1. TGA data for CP1, CP2 and CP3

\begin{tabular}{ccccc}
\hline $\mathrm{CP}$ & $\mathrm{T}\left({ }^{\circ} \mathrm{C}\right)$ & $\Delta \mathrm{m}(\exp ) \mathrm{wt} \%$ & $\Delta \mathrm{m}($ theo $) \mathrm{wt}^{a}{ }^{a}$ & $\mathrm{~T}_{\text {Dec }}\left({ }^{\circ} \mathrm{C}\right)$ \\
\hline $\mathbf{1}$ & $150-250$ & 41 & 41 & 187 \\
$\mathbf{2}$ & $150-250$ & 41 & 41 & 189 \\
$\mathbf{3}$ & $170-270$ & 28 & 25 & 214 \\
\hline
\end{tabular}

${ }^{a}$ assuming a ligand loss

\section{Photophysical properties}

CP1 and CP2 are found non-emissive, which corroborates the trend observed in the literature. ${ }^{11}$ However, the unprecedented motif of the $\mathrm{Cu}_{8} \mathrm{I}_{8}$ SBU urged for a detail study of the emission properties (Figure 8). Moreover, the photophysical properties of CP3 (Table 2) were also compared to those for the $0 \mathrm{D}$ cluster $\mathrm{Cu}_{8} \mathrm{I}_{8}\left(\mathrm{~S}(i-\mathrm{Pr})_{2}\right)_{6}{ }^{60}$ and the $\mathrm{CPs}\left[\mathrm{Cu}_{8} \mathrm{I}_{8}(p\right.$ TolS $\left.\left.\left(\mathrm{CH}_{2}\right)_{8} \mathrm{STol}-p\right)_{3}(\mathrm{MeCN})_{2}\right]_{\mathrm{n}}$ and $\left[\mathrm{Cu}_{8} \mathrm{I}_{8}\left(p-\mathrm{TolS}\left(\mathrm{CH}_{2}\right)_{8} \mathrm{STol}-p\right)_{3}(\mathrm{EtCN})_{2}\right]_{\mathrm{n}}{ }^{62} \mathbf{C P 3}$ is strongly luminescent (Figure S14) and exhibits a strong emission band at $534 \mathrm{~nm}$ which red-shifts to 574 $\mathrm{nm}$ upon going from 298 to $77 \mathrm{~K}$ (Figure 8). This low-energy emissive excited state has been previously attributed to a cluster-centered transition for both closed and open $\mathrm{Cu}_{4} \mathrm{I}_{4}$ cubanes. ${ }^{62}$ The emission maxima $\lambda_{\mathrm{e}}$ at $77 \mathrm{~K}$ is red-shifted compared to that found for $\left[\mathrm{Cu}_{8} \mathrm{I}_{8}(p\right.$ TolS $\left.\left.\left(\mathrm{CH}_{2}\right)_{8} \mathrm{STol}-p\right)_{3}(\mathrm{MeCN})_{2}\right]_{\mathrm{n}}$ and $\left[\mathrm{Cu}_{8} \mathrm{I}_{8}\left(p-\mathrm{TolS}\left(\mathrm{CH}_{2}\right)_{8} \mathrm{STol}-p\right)_{3}(\mathrm{EtCN})_{2}\right]_{\mathrm{n}}$. This is fully consistent with a shorter mean $d(\mathrm{Cu}-\mathrm{Cu})$ distance for $\mathbf{C P 3}(2.7139 \AA$ at $150 \mathrm{~K}$ and $2.7270 \AA$ at $200 \mathrm{~K})$ compared to those for $\left[\mathrm{Cu}_{8} \mathrm{I}_{8}\left(p-\mathrm{TolS}\left(\mathrm{CH}_{2}\right)_{8} \mathrm{STol}-p\right)_{3}(\mathrm{MeCN})_{2}\right]_{\mathrm{n}}(2.7494 \AA)$ and $\left[\mathrm{Cu}_{8} \mathrm{I}_{8}(p-\right.$ $\left.\left.\operatorname{TolS}\left(\mathrm{CH}_{2}\right)_{8} \mathrm{STol}-p\right)_{3}(\mathrm{EtCN})_{2}\right]_{\mathrm{n}}(2.7382 \AA)$ at $173 \mathrm{~K}$. The emission maxima $\left(\lambda_{\mathrm{e}}\right)$, quantum yields $\left(\Phi_{\mathrm{e}}\right)$ and lifetimes $\left(\tau_{\mathrm{e}}\right)$ of $\mathbf{C P 3}$ compare somewhat favorably to that for other $\mathrm{Cu}_{8} \mathrm{I}_{8}$-species containing thio-ligands (Table 2). The largest $\Phi_{\mathrm{e}}$ value ever reported for a $\mathrm{Cu}_{8} \mathrm{I}_{8}$-cluster, regardless of the nature of the ligand, is $68 \%{ }^{57}$ However, the most significant difference is the larger full width at half maximum, fwhm, of the emission band $\left(5900 \mathrm{~cm}^{-1}\right)$. This property stems from hot bands originating from thermally populated upper vibronic levels. ${ }^{100}$ Indeed, upon cooling to $77 \mathrm{~K}$, the fwhm decreases to $2900 \mathrm{~cm}^{-1}\left(\Delta \mathrm{fwhm}=3000 \mathrm{~cm}^{-1}\right)$. This $\Delta \mathrm{fwhm}$ is also larger than that for the closed fused dicubanes $\left(500-1800 \mathrm{~cm}^{-1}\right)$, which is associated with the 
presence of a larger number of lower-frequency Frank-Condon active modes in the open dicubane. This feature is consistent with its lower symmetry $\left(\mathrm{C}_{i} v s . \mathrm{C}_{2 h}\right)$ and lesser rigid skeleton.
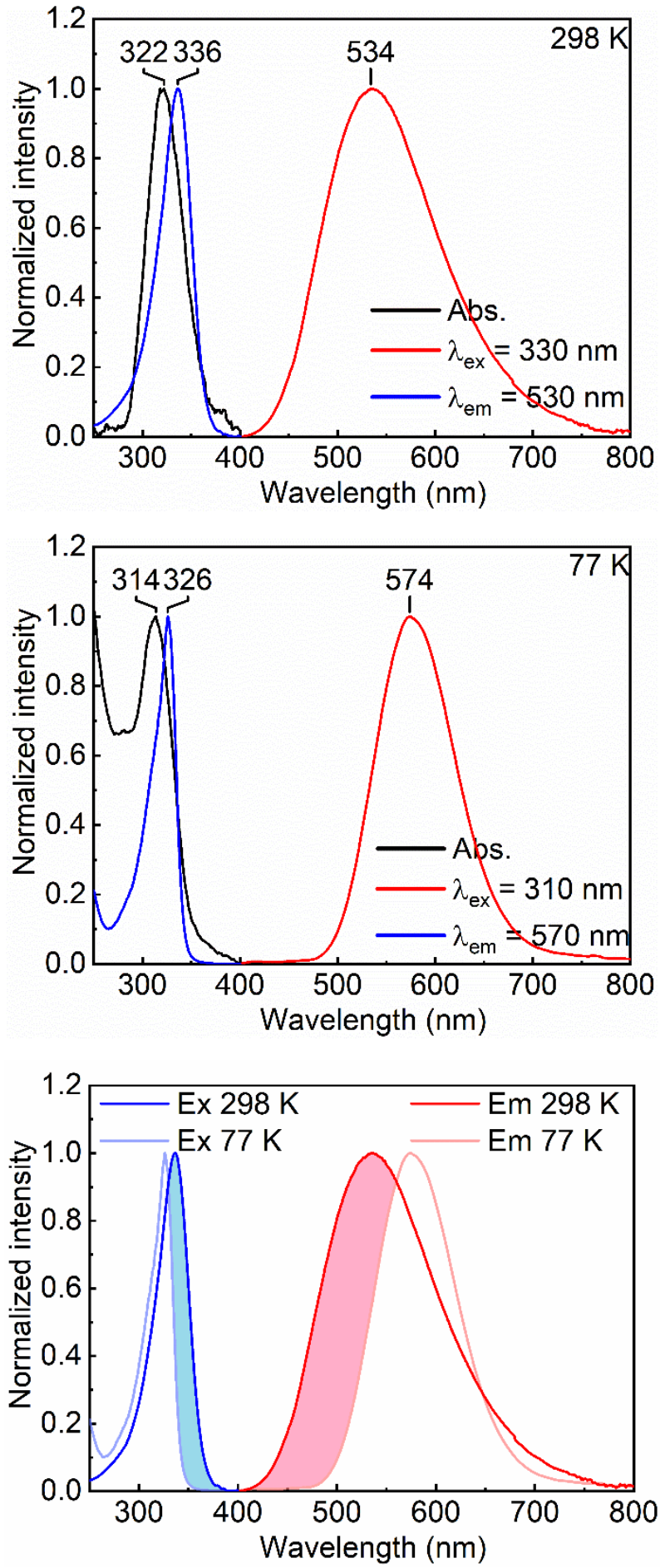

Figure 8. Solid-state emission (red) and excitation (blue) for CP3 at 298 (top) and 77 K (middle) and their overlaps stressing the highlighted regions in color filling associated with the presence 
of "hot bands". Essentially, the contribution of the hot bands is more significant in the open dicubane than that for the closed dicubane (see the $\Delta$ fwhm data in Table 2 and text).

Table 2. Comparison of the photophysical data for CP1, CP2, CP3, CP3 sonicated and CP3@200 20 and literature CPs containing the closed $\mathrm{Cu}_{8} \mathrm{I}_{8}$ SBU.

\begin{tabular}{|c|c|c|c|c|c|c|c|c|c|}
\hline $\mathbf{C P}$ & $\mathrm{T}(\mathrm{K})$ & $\begin{array}{c}\lambda_{\mathrm{em}} \\
(\mathrm{nm})\end{array}$ & $\begin{array}{l}\text { fwhm } \\
\left(\mathrm{cm}^{-1}\right)\end{array}$ & $\begin{array}{c}\Delta \mathrm{fwhm}^{\mathrm{a}} \\
\left(\mathrm{cm}^{-1}\right)\end{array}$ & $\begin{array}{l}\tau_{\mathrm{e}}^{\mathrm{b}} \\
(\mu \mathrm{s})\end{array}$ & $\chi^{2}$ & $\begin{array}{c}\Phi \\
(\%)\end{array}$ & $\begin{array}{c}\mathrm{k}_{\mathrm{r}}^{\mathrm{c}} \\
\left(10^{5} \mathrm{~s}^{-1}\right)\end{array}$ & $\begin{array}{c}\mathrm{k}_{\mathrm{nr}}^{\mathrm{c}} \\
\left(10^{5} \mathrm{~s}^{-1}\right)\end{array}$ \\
\hline \multirow{2}{*}{ CP3 } & 298 & 534 & 5900 & \multirow{2}{*}{3000} & 2.41 & 1.06 & 36 & 1.5 & 2.7 \\
\hline & 77 & 574 & 2900 & & 2.51 & 1.00 & - & - & - \\
\hline \multirow{2}{*}{ CP3 sonicated } & 298 & 539 & 4500 & \multirow{2}{*}{1800} & 2.04 & 1.11 & 40 & 1.9 & 3.0 \\
\hline & 77 & 571 & 2700 & & 1.92 & 1.12 & - & - & - \\
\hline \multirow{2}{*}{ CP3@200C } & 298 & 541 & 4700 & \multirow{2}{*}{2000} & 1.79 & 0.96 & 19 & 1.0 & 4.5 \\
\hline & 77 & 580 & 2700 & & 2.13 & 1.13 & - & - & - \\
\hline \multirow{2}{*}[\mathrm{Cu}_{8}\mathrm{I}_{8}(\mathbf{L2})_{3}(\mathrm{MeCN})_{2}]{$_{\mathrm{n}}{ }^{\mathrm{d}}$} & 298 & 530 & 3400 & \multirow{2}{*}{1600} & 2.72 & $-{ }^{f}$ & 56 & 2.1 & 1.6 \\
\hline & 77 & 538 & 1800 & & 5.27 & $-{ }_{-}^{f}$ & - & - & - \\
\hline \multirow{2}{*}[\mathrm{Cu}_{8}\mathrm{I}_{8}(\mathbf{L}2)_{3}(\mathrm{EtCN})_{2}]{$_{\mathrm{n}}{ }^{\mathrm{d}}$} & 298 & 539 & 3800 & \multirow{2}{*}{1800} & 1.09 & $-{ }^{f}$ & 10 & 0.9 & 8.2 \\
\hline & 77 & 551 & 2000 & & 4.88 & $-{ }^{f}$ & - & - & - \\
\hline \multirow{2}{*}{$\mathrm{Cu}_{8} \mathrm{I}_{8}\left(\mathrm{~S}(i-\mathrm{Pr})_{2}\right)_{6}(0 \mathrm{D})^{\mathrm{e}}$} & 298 & 573 & 3700 & \multirow{2}{*}{500} & 0.20 & $-{ }^{f}$ & 45 & 2.3 & 2.75 \\
\hline & 77 & 532 & 3200 & & 0.26 & $-{ }_{-}^{f}$ & - & - & - \\
\hline
\end{tabular}

${ }^{\mathrm{a}} \Delta_{\mathrm{fwhm}}=($ fwhm $298 \mathrm{~K})-($ fwhm $77 \mathrm{~K})$; fwhm $=$ full width at half maximum. ${ }^{\mathrm{b}}$ The emission decays and curve fittings are provided in Figures S16-S18. ${ }^{\mathrm{c}} \mathrm{k}_{\mathrm{r}}=\frac{\Phi}{\tau_{\mathrm{e}}} ; \mathrm{k}_{n r}=\frac{\mathrm{kr}}{\Phi}(1-\Phi) .{ }^{\mathrm{d}} \mathbf{L} 2=$ $p$-TolS $\left(\mathrm{CH}_{2}\right)_{8} \mathrm{STol}-p$ from ref. 62. From ref. $60 .{ }^{\mathrm{f}}$ Data not reported.

\section{DFT and TDDFT calculations}

The nature of the emissive excited state was addressed by DFT and TDDFT computations. The X-ray data for one $\mathrm{Cu}_{8} \mathrm{I}_{8}(\mathbf{L 1})_{4}$ unit were selected for the calculations (Figures 9 and S20-21)). TDDFT places the spin-allowed lowest energy transition at $312 \mathrm{~nm}$ (Table 3), which compares favorably to the experimental value of 314 at $77 \mathrm{~K}$, a temperature where the presence of hot bands is minimal (Figure 8). This transition is composed mainly of HOMO $\rightarrow$ LUMO (91 \%). These MOs are composed of 88.6 and $11.4 \%$ (HOMO), and 29.8 and $70.2 \%$ (LUMO) of atomic contributions located within $\mathrm{Cu}_{8} \mathrm{I}_{8}$ and L1, respectively (Tables 4 and S4-S5). So, this $\mathrm{S}_{1}$ state is 
best described as metal/halide-to-ligand charge transfer (M/XLCT). Concurrently in the triplet state, the highest and lowest semi-occupied orbitals, HSOMO and LSOMO, exhibit atomic orbital contributions similar to the HOMO and LUMO, respectively, thus indicating that the emissive state is ${ }^{3}(\mathrm{M} / \mathrm{XLCT})^{*}$. This conclusion is the same as that made for the side shared fused closed dicubane version $\left(\mathrm{Cu}_{8} \mathrm{I}_{8} \mathrm{~L}_{6}\right)^{60}$ indicating that breaking two $\mathrm{Cu}-\mathrm{I}$ bonds does not alter the nature of the lowest energy excited states.

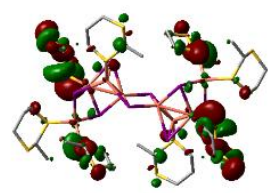

LUMO+4

$(0.03 \mathrm{eV})$

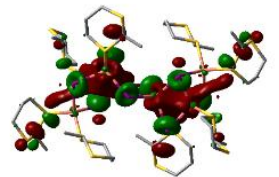

$\mathrm{LUMO}+2$

$(-0.15 \mathrm{eV})$

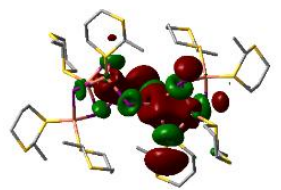

HSOMO

$(-1.05 \mathrm{eV})$

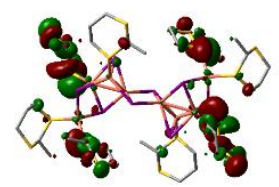

LUMO+3

$(0.01 \mathrm{eV})$

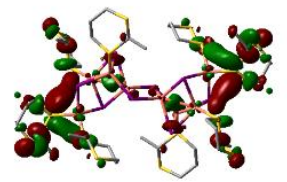

LUMO+1

$(-0.20 \mathrm{eV})$

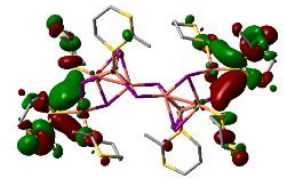

LUMO

$(-0.20 \mathrm{eV})$

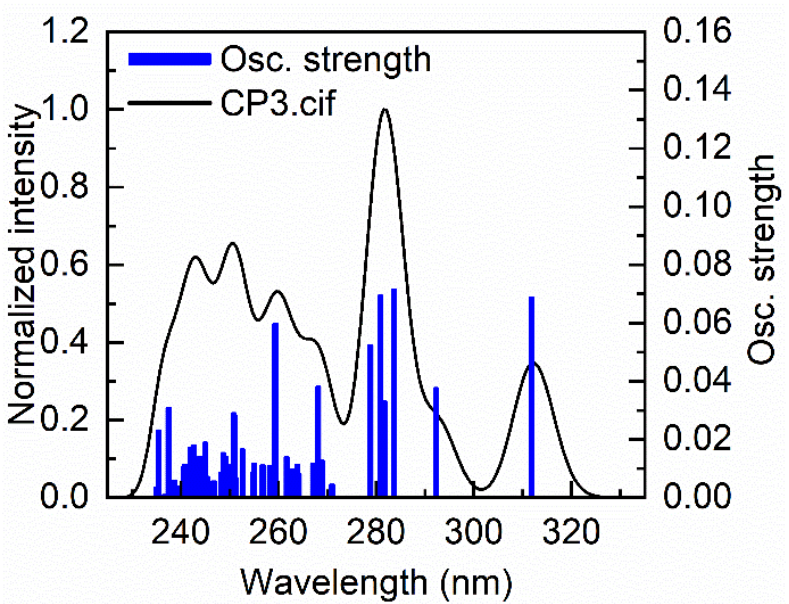

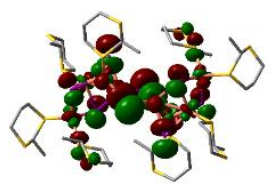

HOMO-3

$(-5.19 \mathrm{eV})$

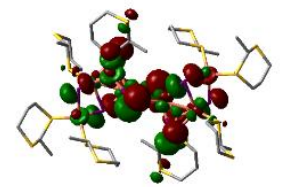

HOMO-1

$(-5.13 \mathrm{eV})$

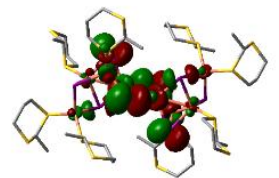

HOMO

$(-4.86 \mathrm{eV})$

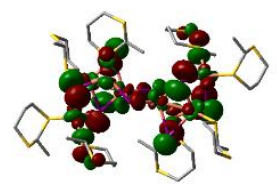

HOMO-4

$(-5.24 \mathrm{eV})$

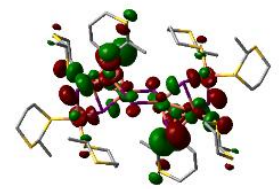

HOMO-2

$(-5.17 \mathrm{eV})$

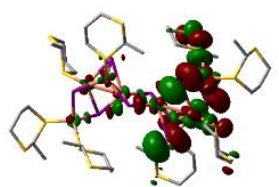

LSOMO

(-5.24 eV)

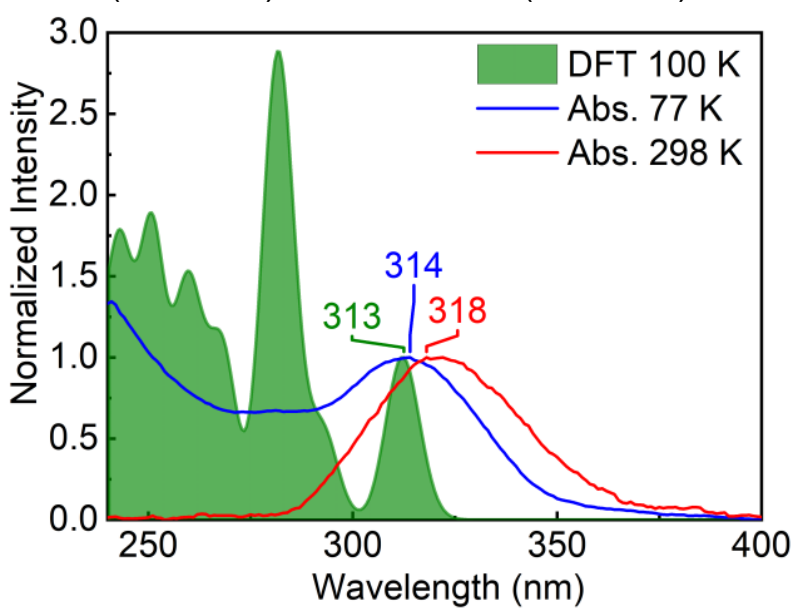

Figure 9. (Top) Representation of the frontier MOs of the $\mathrm{Cu}_{8} \mathrm{I}_{8}$ fragment in CP3. (Bottom) left: bar graph reporting the calculated oscillator strength (f) and calculated position of the $100^{\text {st }}$ electronic transitions calculated by TDDFT for CP3.cif (bar graph; f versus $\lambda$ ). The black line is 
generated by assigning an arbitrary thickness of $1000 \mathrm{~cm}^{-1}$ to each bar. (Right) Stacking of the simulated (green) and experimental solid-state absorption spectrum at 298 (red) and $77 \mathrm{~K}$ (blue). The position of the lowest energy transition matches favorably that for the experimental value of 314 at $77 \mathrm{~K}$.

Table 3. Calculated position, oscillator strength $(f)$ and major contributions of the first five singlet-singlet electronic transitions of CP3

\begin{tabular}{ccl}
\hline$\lambda(\mathrm{nm})$ & $f$ & \multicolumn{1}{c}{ Major contributions $(\%)$} \\
\hline 311.8 & 0.0685 & $\mathrm{HOMO} \rightarrow \mathrm{LUMO}(91)$ \\
296.5 & 0 & $\mathrm{HOMO} \rightarrow \mathrm{L}+1(26), \mathrm{HOMO} \rightarrow \mathrm{L}+3(56)$ \\
293.1 & 0 & $\mathrm{H}-2 \rightarrow \mathrm{LUMO}(68), \mathrm{H}-1 \rightarrow \mathrm{L}+3(17)$ \\
292.2 & 0.0375 & $\mathrm{H}-2 \rightarrow \mathrm{L}+3(21), \mathrm{H}-1 \rightarrow \mathrm{LUMO}(63)$ \\
284.1 & 0 & $\mathrm{HOMO} \rightarrow \mathrm{L}+1(56), \mathrm{HOMO} \rightarrow \mathrm{L}+3(21)$ \\
\hline
\end{tabular}

${ }^{a}$ The first 100 computed electronic transitions are given in the SI (Table S4)

Table 4. Atomic distributions of the frontier MOs for CP3.

\begin{tabular}{lllllllllll}
\hline & $\mathrm{H}-4$ & $\mathrm{H}-3$ & $\mathrm{H}-2$ & $\mathrm{H}-1$ & HOMO & LUMO & $\mathrm{L}+1$ & $\mathrm{~L}+2$ & $\mathrm{~L}+3$ & $\mathrm{~L}+4$ \\
\hline $\mathrm{Cu}_{8} \mathrm{I}_{8}$ & 62.1 & 80.9 & 64.7 & 72.5 & 88.6 & 29.8 & 36.8 & 71.4 & 28.2 & 36.9 \\
$\mathbf{L 1}$ & 37.9 & 19.1 & 35.3 & 27.5 & 11.4 & 70.2 & 63.2 & 28.6 & 71.8 & 63.1 \\
\hline
\end{tabular}

\section{Attempt to convert CP3 into closed dicubane}

This unprecedented $\mathrm{Cu}_{8} \mathrm{I}_{8}$ motif urged for a tentative conversion into its closed version. Indeed, attempts were made to convert this open dicubane into a closed one by both thermal annealing at $140{ }^{\circ} \mathrm{C}$ or by sonication of CP3 (Figures S4 and S5). This temperature was chosen based on TGA and DSC experiments (vide supra) showing that $\mathbf{C P 3}$ is stable up to $170^{\circ} \mathrm{C}$ where it starts losing the ligand. The effects of sonication and thermal annealing on CP3 were monitored by PXRD (Figures 10 and S4-S8), emission and excitation spectra (Figures S15, S16) and lifetime measurements (Table 2, Figures S17-S19). The PXRD patterns show that the main scatterings remain intact but smaller ones either decrease upon thermal annealing and increases upon sonication when compared to the native CP3 (Figure 10). This behavior indicates that new reflection planes are created upon sonication and removed upon heating meaning that the former 
leads to fragmentation of the particles and thermal annealing fuses them. As expected, the photophysical properties vary a little (Table 2 , Figures $\mathrm{S} 14, \mathrm{~S} 15$ ), and the $\mathrm{Cu}_{8} \mathrm{I}_{8}$ geometry remains intact. This relative robustness is consistent with the large density of the solid $\left(3.014 \mathrm{~g} / \mathrm{cm}^{3}\right)$ compared to 2.45 for $\mathbf{C P 1}$ and $2.34 \mathrm{~g} / \mathrm{cm}^{3}$ for $\mathbf{C P 2}(100 \mathrm{~K})$, where large crystal re-organization is readily precluded.

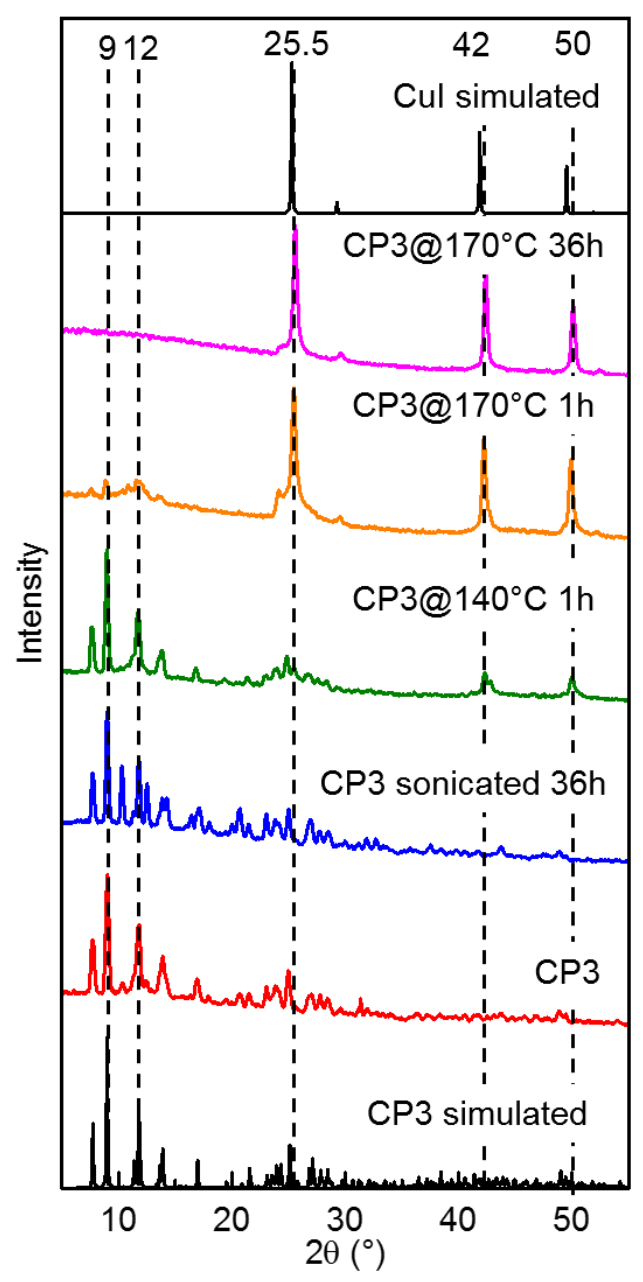

Figure 10. Monitoring of the PXRD patterns of CP3 treated under various conditions (red $=$ native).

Finally, upon further heating up to $170^{\circ} \mathrm{C}$ for $36 \mathrm{~h}$, the PXRD pattern (Figures S6-8) provides evidence for the formation of $\gamma$-CuI. ${ }^{100}$ This reaction path is not unprecedented, ${ }^{101}$ and altogether the open $\mathrm{Cu}_{8} \mathrm{I}_{8}$ dicubane could not be converted into the closed one. 


\section{CONCLUSION}

The use of the $\mathrm{CuX}$ salt specifically where $\mathrm{X}=\mathrm{I}$, and a dithioether ligand exhibiting similar structural traits to DABCO (i.e. both donors are situated inside a 6-membered ring), led to the anticipated formation of a luminescent $3 \mathrm{D} \mathrm{CP}$ incorporating a $\mathrm{Cu}_{8} \mathrm{I}_{8} \mathrm{SBU}$. The statistical approach of literature data stressed in the introduction above to predict the outcome of a $\mathrm{CP}$ formation appears clearly an appealing step towards their rational design. Moreover, the conversion of $\mathbf{C P 1}$ and $\mathbf{C P 2}$, obtained from different routes from the same raw materials, into CP3 indicates that CP3 is the thermodynamic product. However, the observed reversibly CP1 $\leftrightarrow$ CP3 $\leftrightarrow$ CP2 also indicates controlling the nature of the resulting CP. This conclusion also suggests that literature must be filled with CPs that can be further transformed. For instance, just crushing crystals may induce a structural change in both the SBU and CP dimensionality. ${ }^{59}$ The unprecedented structure for a $\mathrm{Cu}_{8} \mathrm{X}_{8}$ cluster is herein the most interesting finding. This open dicubane differs from the closed one by the insertion of two $\mathrm{Cu}-\mathrm{S}$ bonds at the cost of two $\mathrm{Cu}-\mathrm{I}$ ones without altering the remainders within the cluster, resulting into an emissive species using a same ${ }^{3}(\mathrm{M} / \mathrm{XLCT}) *$ manifold. Our open dicubane motif constitutes the "missing link" between the closed cubane-type cluster, the flower basked type $\mathrm{Cu}_{4} \mathrm{I}_{4}$ cluster featuring one broken $\mathrm{Cu}-\mathrm{Cu}$ bond and the open-cubane structure. ${ }^{102,103}$

Attempts to "close" the dicubane failed, which is consistent with the fact that $\mathbf{C P 3}$ is the thermodynamic product and that the $\mathrm{CP}$ is relatively dense. Instead, heating $\mathbf{C P 3}$ at $\mathrm{T}>160{ }^{\circ} \mathrm{C}$ leads to decomposition, with the formation of $\gamma$-CuI. We are currently investigating the coordination chemistry of $\mathbf{L 1}$ vis-à-vis $\mathrm{CuBr}$ and $\mathrm{CuCl}$ and the possibility to built-up luminescent material with dithiane itself and other 2-substituted dithiane derivatives.

\section{ASSOCIATED CONTENT}

Supporting Information. Crystallographic data in CIF file, summary of X-ray data collection and refinement of $\mathbf{C P 1}, \mathbf{C P 2}$ and $\mathbf{C P 3}$, temperature-dependent bond distances for CP3, electronic transition energy, oscillator strength (f) and major contributions of the first 100 singlet-singlet electronic transitions TDDFT calculated for CP3, enlarged PXRD for CP3 upon sonication and annealing, enlarged Raman spectra (PDF). The following files are available free of charge on the ACS publication website at hppt://pubs.acs.org. 


\section{AUTHOR INFORMATION}

\section{Corresponding Author}

* Pierre.Harvey@,USherbrooke.ca

* Michael.Knorr@univ-fcomte.fr

*1ydie.viau@univ-fcomte.fr

\section{Author Contributions}

The manuscript was written through contributions of all authors. All authors have given approval to the final version of the manuscript.

\section{Funding Sources}

This work was supported by the Natural Sciences and Engineering Research Council of Canada, the Fonds de Recherche du Québec-Nature et Technologies, Compute Canada and Calcul Québec, the Centre Quebecois sur les Matériaux Fonctionnels and the CNRS.

\section{REFERENCES}

1. Bezuidenhout, C. X.; Esterhuysen, C.; Barbour, L. J. Solvatochromism as a probe to observe the solvent exchange process in a 1-D porous coordination polymer with 1-D solvent accessible channels. Chem. Commun. 2017, 53, 5618-5621.

2. Du, M.; Li, C.-P.; Chen, M.; Ge, Z.-W.; Wang, X.; Wang, L.; Liu, C.-S. Divergent Kinetic and Thermodynamic Hydration of a Porous $\mathrm{Cu}(\mathrm{II})$ Coordination Polymer with Exclusive CO2 Sorption Selectivity. J. Am. Chem. Soc. 2014, 136, 10906-10909.

3. Elsaidi, S. K.; Mohamed, M. H.; Wojtas, L.; Cairns, A. J.; Eddaoudi, M.; Zaworotko, M. J. Two-step crystal engineering of porous nets from $\mathrm{Cr}_{3}\left(\mu_{3}-\mathrm{O}\right)\left(\mathrm{RCO}_{2}\right)_{6}$ and $\mathrm{Cu}_{3}\left(\mu_{3^{-}}\right.$ $\mathrm{Cl})\left(\mathrm{RNH}_{2}\right)_{6} \mathrm{Cl}_{6}$ molecular building blocks. Chem. Commun. 2013, 49, 8154-8156.

4. Hawes, C. S.; Babarao, R.; Hill, M. R.; White, K. F.; Abrahams, B. F.; Kruger, P. E. Hysteretic carbon dioxide sorption in a novel copper(II)-indazole-carboxylate porous coordination polymer. Chem. Commun. 2012, 48, 11558-11560.

5. Kotani, R.; Kondo, A.; Maeda, K. Gate adsorption of $\mathrm{CO}_{2}$ on a flexible one-dimensional copper-based coordination polymer crystal. Chem. Commun. 2012, 48, 11316-11318.

6. $\quad$ Procopio, E. Q.; Fukushima, T.; Barea, E.; Navarro, J. A. R.; Horike, S.; Kitagawa, S. A Soft Copper(II) Porous Coordination Polymer with Unprecedented Aqua Bridge and Selective Adsorption Properties. Chem. Eur. J. 2012, 18, 13117-13125.

7. Shigematsu, A.; Yamada, T.; Kitagawa, H. Selective Separation of Water, Methanol, and Ethanol by a Porous Coordination Polymer Built with a Flexible Tetrahedral Ligand. J. Am. Chem. Soc. 2012, 134, 13145-13147. 
8. Prochowicz, D.; Justyniak, I.; Kornowicz, A.; Kaczorowski, T.; Kaszkur, Z.; Lewinski, J. Construction of a Porous Homochiral Coordination Polymer with Two Types of $\mathrm{Cu}_{\mathrm{n}} \mathrm{I}_{\mathrm{n}}$ Alternating Units Linked by Quinine: A Solvothermal and a Mechanochemical Approach. Chem. Eur. J. 2012, 18, 7367-7371.

9. Burd, S. D.; Ma, S. Q.; Perman, J. A.; Sikora, B. J.; Snurr, R. Q.; Thallapally, P. K.; Tian, J.; Wojtas, L.; Zaworotko, M. J. Highly Selective Carbon Dioxide Uptake by $\mathrm{Cu}(\mathrm{bpy}-\mathrm{n})_{2}\left(\mathrm{SiF}_{6}\right)$ (bpy-1=4,4 '-Bipyridine; bpy-2=1,2-Bis(4-pyridyl)ethene). J. Am. Chem. Soc. 2012, 134, 36633666.

10. Meilikhov, M.; Furukawa, S.; Hirai, K.; Fischer, R. A.; Kitagawa, S. Binary Janus Porous Coordination Polymer Coating for Sensor Devices with Tunable Analyte Affinity. Angew. Chem. Int. Ed. 2013, 52, 341-345.

11. Varju, B. R.; Ovens, J. S.; Leznoff, D. B. Mixed Cu(I)/Au(I) coordination polymers as reversible turn-on vapoluminescent sensors for volatile thioethers. Chem. Commun. 2017, 53, 6500-6503.

12. Liu, S. Y.; Qi, X. L.; Lin, R. B.; Cheng, X. N.; Liao, P. Q.; Zhang, J. P.; Chen, X. M. Porous $\mathrm{Cu}(\mathrm{I})$ Triazolate Framework and Derived Hybrid Membrane with Exceptionally High Sensing Effi ciency for Gaseous Oxygen. Adv. Funct. Mater. 2014, 24, 5866-5872.

13. Wen, T.; Zhang, D.-X.; Liu, J.; Lin, R.; Zhang, J. A multifunctional helical Cu(I) coordination polymer with mechanochromic, sensing and photocatalytic properties. Chem. Commun. 2013, 49, 5660-5662.

14. Song, Y.; Fan, R.; Du, X.; Xing, K.; Dong, Y.; Wang, P.; Yang, Y. Dual functional fluorescent sensor for selectively detecting acetone and $\mathrm{Fe}^{3+}$ based on $\left\{\mathrm{Cu}_{2} \mathrm{~N}_{4}\right\}$ substructure bridged $\mathrm{Cu}(\mathrm{I})$ coordination polymer. RSC Adances 2016, 6, 110182-110189.

15. Zhang, W.; Jin, W.; Fukushima, T.; Mori, T.; Aida, T. Helix Sense-Selective Supramolecular Polymerization Seeded by a One-Handed Helical Polymeric Assembly. J. Am. Chem. Soc. 2015, 137, 13792-13795.

16. Veselska, O.; Podbevsek, D.; Ledoux, G.; Fateeva, A.; Demessence, A. Intrinsic tripleemitting 2D copper thiolate coordination polymer as a ratiometric thermometer working over $400 \mathrm{~K}$ range. Chem. Commun. 2017, 53, 12225-12228.

17. Kim, T. H.; Shin, Y. W.; Jung, J. H.; Kim, J. S.; Kim, J. Crystal-to-crystal transformation between three $\mathrm{Cu}-\mathrm{I}$ coordination polymers and structural evidence for luminescence thermochromism. Angew. Chem. Int. Ed. 2008, 47, 685-688.

18. Zhan, S.-Z.; Li, M.; Zhou, X.-P.; Wang, J.-H.; Yang, J.-R.; Li, D. When $\mathrm{Cu}_{4} \mathrm{I}_{4}$ cubane meets $\mathrm{Cu}_{3}$ (pyrazolate) ${ }_{3}$ triangle: dynamic interplay between two classical luminophores functioning in a reversibly thermochromic coordination polymer. Chem. Commun. 2011, 47, 12441-12443.

19. Troyano, J.; Perles, J.; Amo-Ochoa, P.; Ignacio Martinez, J.; Concepcion Gimeno, M.; Fernandez-Moreira, V.; Zamora, F.; Delgado, S. Luminescent Thermochromism of 2D Coordination Polymers Based on Copper(I) Halides with 4-Hydroxythiophenol. Chem. Eur. J. 2016, 22, 18027-18035.

20. Coronado, E.; Gimenez-Marques, M.; Espallargas, G. M.; Brammer, L. Tuning the magneto-structural properties of non-porous coordination polymers by $\mathrm{HCl}$ chemisorption. Nat. Commun. 2012, 3, 8.

21. Zhu, M.; Yang, M.; Wang, J.; Li, H.; Li, L. Structural and Magnetic Properties of 2p-3d4f Hetero-Tri-Spin Chains Comprising $\left\{\mathrm{Cu}(\mathrm{hfac})_{2} \text {-Radical }\right\}_{2}$ Dimers and $\mathrm{Ln}(\mathrm{hfac})_{3}$ (hfac=hexafluoroacetylacetonate). Chem. Asian J. 2016, 11, 1900-1905. 
22. Amacher, A. M.; Puigmarti-Luis, J.; Geng, Y.; Lebedev, V.; Laukhin, V.; Kraemer, K.; Hauser, J.; Amabilino, D. B.; Decurtins, S.; Liu, S.-X. Coordination-directed self-assembly of a simple benzothiadiazole-fused tetrathiafulvalene to low-bandgap metallogels. Chem. Commun. 2015, 51, 15063-15066.

23. Qin, Y.-L.; Yao, R.-X.; Wu, G.-X.; Liu, M.-M.; Zhang, X.-M. Heterometallic MixedValence Copper(I,II) Cyanides that were Tuned by Using the Chelate Effect: Discovery of Famous Cairo Pentagonal Tiling and Unprecedented $(3,4)$-Connected $\left\{8^{3}\right\}_{2}\left\{8^{6}\right\}$ Topological 3D Net. Chem. Asian J. 2013, 8, 1587-1595.

24. Prescimone, A.; Morien, C.; Allan, D.; Schlueter, J. A.; Tozer, S. W.; Manson, J. L.; Parsons, S.; Brechin, E. K.; Hill, S. Pressure-Driven Orbital Reorientations and CoordinationSphere Reconstructions in $\mathrm{CuF}_{2}\left(\mathrm{H}_{2} \mathrm{O}\right)_{2}$ (pyz). Angew. Chem. Int. Ed. 2012, 51, 7490-7494.

25. Huang, X.; Zhang, S.; Liu, L. Y.; Yu, L.; Chen, G. F.; Xu, W.; Zhu, D. B. Superconductivity in a Copper(II)-Based Coordination Polymer with Perfect Kagome Structure. Angew. Chem. Int. Ed. 2018, 57, 146-150.

26. Amo-Ochoa, P.; Hassanein, K.; Gomez-Garcia, C. J.; Benmansour, S.; Perles, J.; Castillo, O.; Martinez, J. I.; Ocon, P.; Zamora, F. Reversible stimulus-responsive $\mathrm{Cu}(\mathrm{I})$ iodide pyridine coordination polymer. Chem. Commun. 2015, 51, 14306-14309.

27. Huang, X.; Sheng, P.; Tu, Z.; Zhang, F.; Wang, J.; Geng, H.; Zou, Y.; Di, C.-a.; Yi, Y.; Sun, Y.; Xu, W.; Zhu, D. A two-dimensional pi-d conjugated coordination polymer with extremely high electrical conductivity and ambipolar transport behaviour. Nat. Commun. 2015, 6.

28. Okubo, T.; Anma, H.; Tanaka, N.; Himoto, K.; Seki, S.; Saeki, A.; Maekawa, M.; Kuroda-Sowa, T. Crystal structure and carrier transport properties of a new semiconducting 2D coordination polymer with a 3,5-dimethylpiperidine dithiocarbamate ligand. Chem. Commun. 2013, 49, 4316-4318.

29. de Hatten, X.; Asil, D.; Friend, R. H.; Nitschke, J. R. Aqueous Self-Assembly of an Electroluminescent Double-Helical Metallopolymer. J. Am. Chem. Soc. 2012, 134, 19170-19178. 30. Fadaee, F.; Amirnasr, M.; Prsa, K.; Pattison, P.; Shaik, N. E.; Ronnow, H. M.; Esrafili, M. D.; Omrani, A. A.; Amiri, A.; Schenk-Joss, K. Intrachain antiferromagnetic exchange in a 1D branched-chain built of two different copper(II) centres interlinked by end-on azido and phenoxo bridges: electron density map, electrochemical and magnetic properties. RSC Adances 2015, 5, 59926-59934.

31. Wen, T.; Zhang, D.-X.; Zhang, H.-X.; Zhang, H.-B.; Zhang, J.; Li, D.-S. Redox-active $\mathrm{Cu}(\mathrm{I})$ boron imidazolate framework for mechanochromic and catalytic applications. Chem. Commun. 2014, 50, 8754-8756.

32. Zakaria, M. B.; Hu, M.; Tsujimoto, Y.; Sakka, Y.; Suzuki, N.; Kamachi, Y.; Imura, M.; Ishihara, S.; Ariga, K.; Yamauchi, Y. Controlled Crystallization of Cyano-Bridged Cu-Pt Coordination Polymers with Two-Dimensional Morphology. Chem. Asian J. 2014, 9, 1511-1514. 33. Hou, Y.-L.; Sun, R. W.-Y.; Zhou, X.-P.; Wang, J.-H.; Li, D. A copper(I)/copper(II)-salen coordination polymer as a bimetallic catalyst for three-component Strecker reactions and degradation of organic dyes. Chem. Commun. 2014, 50, 2295-2297.

34. Chen, X.; Li, H. X.; Zhang, Z. Y.; Zhao, W.; Lang, J. P.; Abrahams, B. F. Activation and amplification of the third-order NLO and luminescent responses of a precursor cluster by a supramolecular approach. Chem. Commun. 2012, 48, 4480-4482.

35. Zhang, J. F.; Jia, D.; Humphrey, M. G.; Meng, S. C.; Zaworotko, M. J.; Cifuentes, M. P.; Zhang, C. Ammonium-crown ether supramolecular cation-templated assembly of an 
unprecedented heterobicluster-metal coordination polymer with enhanced NLO properties. Chem. Commun. 2016, 52, 3797-3800.

36. Gallego, A.; Hermosa, C.; Castillo, O.; Berlanga, I.; Gomez-Garcia, C. J.; Mateo-Marti, E.; Martinez, J. I.; Flores, F.; Gomez-Navarro, C.; Gomez-Herrero, J.; Delgado, S.; Zamora, F. Solvent-Induced Delamination of a Multifunctional Two Dimensional Coordination Polymer. Adv. Mater. 2013, 25, 2141-2146.

37. Wen, T.; Zhou, X.-P.; Zhang, D.-X.; Li, D. Luminescent Mechanochromic Porous Coordination Polymers. Chem. Eur. J. 2014, 20, 644-648.

38. Cho, S.; Jeon, Y.; Lee, S.; Kim, J.; Kim, T. H. Reversible Transformation between Cubane and Stairstep Cu4I4 Clusters Using Heat or Solvent Vapor. Chem. Eur. J. 2015, 21, 1439-1443.

39. Raghuvanshi, A.; Strohmann, C.; Tissot, J.-B.; Clement, S.; Mehdi, A.; Richeter, S.; Viau, L.; Knorr, M. Assembly of Coordination Polymers Using Thioether-Functionalized Octasilsesquioxanes: Occurrence of $(\mathrm{CuX})_{\mathrm{n}}$ Clusters $(\mathrm{X}=\mathrm{Br}$ and I) within 3D-POSS Networks. Chem. Eur. J. 2017, 23, 16479-16483.

40. $\quad$ Spielberg, E. T.; Edengeiser, E.; Mallick, B.; Havenith, M.; Mudring, A. V. (1-Butyl-4methyl- pyridinium) $\mathrm{Cu}(\mathrm{SCN})_{2}$ : A Coordination Polymer and Ionic Liquid. Chem. Eur. J. 2014, 20, 5338-5345.

41. Harvey, P. D.; Knorr, M. Luminescent Coordination Polymers Built Upon $\mathrm{Cu}_{4} \mathrm{X}_{4}(\mathrm{X}=$ Br,I) Clusters and Mono- and Dithioethers. Macromol. Rapid Commun. 2010, 31, 808-826.

42. Peng, R.; Li, M.; Li, D. Copper(I) halides: A versatile family in coordination chemistry and crystal engineering. Coord. Chem. Rev. 2010, 254, 1-18.

43. Wachter, J.; 2013; Vol. 1, p 933.

44. Harvey, P. D.; Knorr, M. Stabilization of $(\mathrm{CuX})_{\mathrm{n}}$ Clusters $(\mathrm{X}=\mathrm{Cl}, \mathrm{Br}$, I; $\mathrm{n}=2,4,5,6,8)$ in Mono- and Dithioether-Containing Layered Coordination Polymers. J. Cluster Sci. 2015, 26, 411-459.

45. Harvey, P. D.; Knorr, M. Designs of 3-Dimensional Networks and MOFs Using Monoand Polymetallic Copper(I) Secondary Building Units and Mono- and Polythioethers: Materials Based on the Cu-S Coordination Bond. J. Inorg. Organomet. Polym. Mater. 2016, 26, 11741197.

46. Liu, Q.; Zhang, W.-H.; Lang, J.-P. Versatile thiomolybdate(thiotungstate)-copper-sulfide clusters and multidimensional polymers linked by cyanides. Coord. Chem. Rev. 2017, 350, 248274.

47. Liu, S.-Y.; Zhang, J.-P.; Chen, X.-M. Cu(I) 3,5-Diethyl-1,2,4-Triazolate (MAF-2): From Crystal Engineering to Multifunctional Materials. Cryst. Growth Des. 2017, 17, 1441-1449.

48. Lapprand, A.; Bonnot, A.; Knorr, M.; Rousselin, Y.; Kubicki, M. M.; Fortin, D.; Harvey, P. D. Formation of an unprecedented $(\mathrm{CuBr})_{5}$ cluster and a zeolite-type 2D-coordination polymer: a surprising halide effect. Chem. Commun. 2013, 49, 8848-8850.

49. Juvenal, F.; Langlois, A.; Bonnot, A.; Fortin, D.; Harvey, P. D. Luminescent 1D-and 2DCoordination Polymers Using $\mathrm{CuX}$ Salts $(\mathrm{X}=\mathrm{Cl}, \mathrm{Br}, \mathrm{I})$ and a Metal-Containing Dithioether Ligand. Inorg. Chem. 2016, 55, 11096-11109.

50. Juvenal, F.; Bonnot, A.; Fortin, D.; Harvey, P. D. The trans-Bis(pthioetherphenylacetynyl)bis(phosphine)platinum(II) Ligands: A Step towards Predictability and Crystal Design. ACS Omega 2017, 2, 7433-7443. 
51. Bi, M.; Li, G.; Hua, J.; Liu, Y.; Liu, X.; Hu, Y.; Shi, Z.; Feng, S. Two isomers with FSC topology constructed from $\mathrm{Cu}_{6} \mathrm{I}_{6}(\mathrm{DABCO})_{4}$ and $\mathrm{Cu}_{8} \mathrm{I}_{8}(\mathrm{DABCO})_{6}$ building blocks. Cryst. Growth Des. 2007, 7, 2066-2070.

52. Wang, J.; Zheng, S.-L.; Hu, S.; Zhang, Y.-H.; Tong, M.-L. New in situ cleavage of both $\mathrm{S}-\mathrm{S}$ and $\mathrm{S}-\mathrm{C}\left(\mathrm{sp}_{2}\right)$ bonds and rearrangement reactions toward the construction of copper(I) cluster-based coordination networks. Inorg. Chem. 2007, 46, 795-800.

53. Hou, Q.; Yu, J.-H.; Xu, J.-N.; Yang, Q.-F.; Xu, J.-Q. A new 3-D two-fold interpenetrated framework with sqp net based on $\mathrm{Cu}_{6} \mathrm{I}_{6}$ and $\mathrm{Cu}_{8} \mathrm{I}_{8}$ cluster nodes. CrystEngComm 2009, 11, 24522455.

54. Bai, S.-Q.; Kwang, J. Y.; Koh, L. L.; Young, D. J.; Hor, T. S. A. Functionalized 1,2,3triazoles as building blocks for photoluminescent POLOs (polymers of oligomers) of copper(I). Dalton Trans. 2010, 39, 2631-2636.

55. Zhang, Y.; Wu, T.; Liu, R.; Dou, T.; Bu, X.; Feng, P. Three-Dimensional Photoluminescent Frameworks Constructed from Size-Tunable CuI Clusters. Cryst. Growth Des. 2010, 10, 2047-2049.

56. Zeng, G.; Xing, S.; Wang, X.; Yang, Y.; Ma, D.; Liang, H.; Gao, L.; Hua, J.; Li, G.; Shi, Z.; Feng, S. 3d-4f Metal-Organic Framework with Dual Luminescent Centers That Efficiently Discriminates the Isomer and Homologues of Small Organic Molecules. Inorg. Chem. 2016, 55, 1089-1095.

57. Zeng, G.; Xing, S.; Wang, X.; Yang, Y.; Xiao, Y.; Li, Z.; Li, G.; Shi, Z.; Feng, S. Synthesis, structures and luminescence properties of 3d-4f heterometallic-organic frameworks (HMOFs) constructed from different copper halide clusters. CrystEngComm 2016, 18, 43364342 .

58. Song, Y.; Fan, R.-Q.; Xing, K.; Du, X.; Su, T.; Wang, P.; Yang, Y.-L. Insight into the Controllable Synthesis of $\mathrm{Cu}(\mathrm{I}) / \mathrm{Cu}(\mathrm{II})$ Metal-Organic Complexes: Size-Exclusive Selective Dye Adsorption and Semiconductor Properties. Cryst. Growth Des. 2017, 17, 2549-2559.

59. Shan, X.-C.; Zhang, H.-B.; Chen, L.; Wu, M.-Y.; Jiang, F.-L.; Hong, M.-C. MultistimuliResponsive Luminescent Material Reversible Switching Colors via Temperature and Mechanical Force. Cryst. Growth Des. 2013, 13, 1377-1381.

60. Knorr, M.; Bonnot, A.; Lapprand, A.; Khatyr, A.; Strohmann, C.; Kubicki, M. M.; Rousselin, Y.; Harvey, P. D. Reactivity of CuI and $\mathrm{CuBr}$ toward Dialkyl Sulfides RSR: From Discrete Molecular $\mathrm{Cu}_{4} \mathrm{I}_{4} \mathrm{~S}_{4}$ and $\mathrm{Cu}_{8} \mathrm{I}_{8} \mathrm{~S}_{6}$ Clusters to Luminescent Copper(I) Coordination Polymers. Inorg. Chem. 2015, 54, 4076-4093.

61. Harvey, P. D.; Bonnot, A.; Lapprand, A.; Strohmann, C.; Knorr, M. Coordination $\mathrm{RC}_{6} \mathrm{H}_{4} \mathrm{~S}\left(\mathrm{CH}_{2}\right)_{8} \mathrm{SC}_{6} \mathrm{H}_{4} \mathrm{R} /(\mathrm{CuI})_{\mathrm{n}}$ Polymers $(\mathrm{R}(\mathrm{n})=\mathrm{H}(4) ; \mathrm{Me}(8))$ : An Innocent Methyl Group that Makes the Difference. Macromol. Rapid Commun. 2015, 36, 654-659.

62. Bonnot, A.; Juvenal, F.; Lapprand, A.; Fortin, D.; Knorr, M.; Harvey, P. D. Can a highly flexible copper(I) cluster-containing 1D and 2D coordination polymers exhibit MOF-like properties? Dalton Trans. 2016, 45, 11413-11421.

63. Takemura, Y.; Nakajima, T.; Tanase, T. Interconversion between ladder-type octanuclear and linear tetranuclear copper(I) complexes supported by tetraphosphine ligands. Dalton Trans. 2009, 10231-10243.

64. Cheng, Y.; Xu, P.; Ding, Y.-B.; Yin, Y.-G. Stoichiometry-dominated in situ formation of iodocuprate clusters and dimethyl-2,2 '-biimidazoles as building units of coordination architectures. CrystEngComm 2011, 13, 2644-2648. 
65. Kursheva, L. I.; Kataeva, O. N.; Gubaidullin, A. T.; Khasyanzyanova, F. S.; Vakhitov, E. V.; Krivolapov, D. B.; Batyeva, E. S. Triisopropyl phosphorotrithioite as a monodantate and a tridentate ligand in complexes with copper(I) halides. Russ. J. Gen. Chem. 2003, 73, 1516-1521. 66. Goreshnik, E. A.; Ciunik, L. Z.; Gorelenko, Y. K.; Mys'kiv, M. G. Complexation of the 2,4,6-triallyloxy-1,3,5-triazine with copper(I,II) chlorides. Syntheses and crystal structures of $\left[\mathrm{CuCl}_{2} \cdot 2 \mathrm{C}_{3} \mathrm{~N}_{3}\left(\mathrm{OC}_{3} \mathrm{H}_{5}\right)_{3}\right],\left[\mathrm{Cu}_{7} \mathrm{Cl}_{8} \cdot 2 \mathrm{C}_{3} \mathrm{~N}_{3}\left(\mathrm{OC}_{3} \mathrm{H}_{5}\right)_{3}\right]$, and $\left[\mathrm{Cu}_{8} \mathrm{Cl}_{8} \cdot 2 \mathrm{C}_{3} \mathrm{~N}_{3}\left(\mathrm{OC}_{3} \mathrm{H}_{5}\right)_{3} \cdot 2 \mathrm{C}_{2} \mathrm{H}_{5} \mathrm{OH}\right.$. Z. Anorg. Allg. Chem. 2004, 630, 2743-2748.

67. Knorr, M.; Khatyr, A.; Aleo, A. D.; El Yaagoubi, A.; Strohmann, C.; Kubicki, M. M.; Rousselin, Y.; Aly, S. M.; Fortin, D.; Lapprand, A.; Harvey, P. D. Copper(I) Halides (X = Br, I) Coordinated to Bis(arylthio)methane Ligands: Aryl Substitution and Halide Effects on the Dimensionality, Cluster Size, and Luminescence Properties of the Coordination Polymers. Crystal Growth \& Design 2014, 14, 5373-5387.

68. Martinez-Alanis, P. R.; Ugalde-Saldivar, V. M.; Castillo, I. Electrochemical and Structural Characterization of Tri- and Dithioether Copper Complexes. Eur. J. Inorg. Chem. 2011, 212-220.

69. Knaust, J. M.; Keller, S. W. Supermolecular coordination isomers: synthesis and crystal structures of four new one-dimensional copper(I) coordination polymers with 1,3-dithiane. CrystEngComm 2003, 5, 459-465.

70. Frisch, M. J.; Trucks, G. W.; Schlegel, H. B.; Scuseria, G. E.; Robb, M. A.; Cheeseman, J. R.; Montgomery Jr, J. A.; Vreven, T. K. K. N.; LKudin, K. N.; Burant, J. C.; Millam, J. M. Gaussian 09. Wallingford, CT, 2004.

71. Hohenberg, P.; Kohn, W. Inhomogeneous electron gas. Physical Review B 1964, 136, B864-+.

72. Hohenberg, P.; Kohn, W. J. Phys. Rev. 1965, 140, A1133.

73. Lee, C. T.; Yang, W. T.; Parr, R. G. Development of the Colle-Salvetti correlation-energy formula into a functionnal of the electron-density. Physical Review B 1988, 37, 785-789.

74. Miehlich, B.; Savin, A.; Stoll, H.; Preuss, H. Results obtained with the correlation-energy density functionals of Becke and lee, Yang and Parr. Chem. Phys. Lett. 1989, 157, 200-206.

75. Parr, R. G.; Yang, W. Density-functionnal theory of atoms and molecules. Oxfor Univ. Press, Oxford U.K., 1989.

76. Salahub, D. R.; Zerner, M. C. The Challenge of $d$ and $f$ Electrons, . Amer. Chem. Soc. Washington, D.C.: 1989.

77. Becke, A. D. Density-functional thermochemistry 3. The role of exact exchange. $J$. Chem. Phys. 1993, 98, 5648-5652.

78. Bauernschmitt, R.; Ahlrichs, R. Treatment of electronic excitations within the adiabatic approximation of time dependent density functional theory. Chem. Phys. Lett. 1996, 256, 454464.

79. Casida, M. E.; Jamorski, C.; Casida, K. C.; Salahub, D. R. Molecular excitation energies to high-lying bound states from time-dependent density-functional response theory: Characterization and correction of the time-dependent local density approximation ionization threshold. J. Chem. Phys. 1998, 108, 4439-4449.

80. Stratmann, R. E.; Scuseria, G. E.; Frisch, M. J. An efficient implementation of timedependent density-functional theory for the calculation of excitation energies of large molecules. J. Chem. Phys. 1998, 109, 8218-8224.

81. Binkley, J. S.; Pople, J. A.; Hehre, W. J. self-consistent molecular orbital methods. 21. Small split-Valence basis-sets for 1st row elements. J. Am. Chem. Soc. 1980, 102, 939-947. 
82. Gordon, M. S.; Binkley, J. S.; Pople, J. A.; Pietro, W. J.; Hehre, W. J. self-consistent molecular-orbital methods .22. small split-valence basis-sets for 2nd-row elements. J. Am. Chem. Soc. 1982, 104, 2797-2803.

83. Pietro, W. J.; Francl, M. M.; Hehre, W. J.; Defrees, D. J.; Pople, J. A.; Binkley, J. S. selfconsistent molecular-orbital methods .24. supplemented small split-valence basis-sets for 2ndrow elements. J. Am. Chem. Soc. 1982, 104, 5039-5048.

84. Dobbs, K. D.; Hehre, W. J. molecular-orbital theory of the properties of inorganic and organometallic compounds 4 - extended basis-sets for 3rd-row and 4th-row, main-group elements. J. Comput. Chem. 1986, 7, 359-378.

85. Dobbs, K. D.; Hehre, W. J. molecular-orbital theory of the properties of inorganic and organometallic compounds .5. extended basis-sets for 1st-row transition-metals. J. Comput. Chem. 1987, 8, 861-879.

86. Dobbs, K. D.; Hehre, W. J. molecular-orbital theory of the properties of inorganic and organometallic compounds .6. extended basis-sets for 2nd-row transition-metals. J. Comput. Chem. 1987, 8, 880-893.

87. O'Boyle, N. M.; Tenderholt, A. L.; Langner, K. M. cclib: A library for packageindependent computational chemistry algorithms. J. Comput. Chem. 2008, 29, 839-845.

88. Munakata, M.; Wu, L. P.; Kuroda-Sowa, T.; Maekawa, M.; Suenaga, Y.; Nakagawa, S. One-, two- and three-dimensional copper(I) and silver(I) complexes of 2,11dithia[3.3]paracyclophane. J. Chem. Soc., Dalton Trans. 1996, 1525-30.

89. Maelger, H.; Olbrich, F.; Kopf, J.; Abeln, D.; Weiss, E. Synthesis and crystal structure of Lewis base adducts of copper(I)-halides with dimethyl sulfide and tetrahydrothiophene. Zeitschrift fuer Naturforschung, B: Chemical Sciences 1992, 47, 1276-80.

90. Lu, W.; Yan, Z.-M.; Dai, J.; Zhang, Y.; Zhu, Q.-Y.; Jia, D.-X.; Guo, W.-J. Coordination Assembly of TTF Derivatives through CuI Bridges. Eur. J. Inorg. Chem. 2005, 2339-2345.

91. Knorr, M.; Guyon, F.; Khatyr, A.; Allain, M.; Aly, S. M.; Lapprand, A.; Fortin, D.; Harvey, P. D. Unexpected Formation of a Doubly Bridged Cyclo-1,2-dithian 1D Coordination $\mathrm{Cu}_{2} \mathrm{I}_{2}$-Containing Luminescent Polymer. J. Inorg. Organomet. Polym. Mater. 2010, 20, 534-543.

92. Knorr, M.; Guyon, F.; Khatyr, A.; Strohmann, C.; Allain, M.; Aly, S. M.; Lapprand, A.; Fortin, D.; Harvey, P. D. Construction of $(\mathrm{CuX})_{2}$ Cluster-Containing $(\mathrm{X}=\mathrm{Br}, \mathrm{I} ; \mathrm{n}=1,2)$ Coordination Polymers Assembled by Dithioethers $\operatorname{ArS}\left(\mathrm{CH}_{2}\right)_{\mathrm{m}} \mathrm{SAr}(\mathrm{Ar}=\mathrm{Ph}, \mathrm{p}-\mathrm{Tol} ; \mathrm{m}=3,5)$ : Effect of the Spacer Length, Aryl Group, and Metal-to-Ligand Ratio on the Dimensionality, Cluster Nuclearity, and the Luminescence Properties of the Metal-Organic Frameworks. Inorg. Chem. 2012, 51, 9917-9934.

93. Peindy, H. N.; Guyon, F.; Khatyr, A.; Knorr, M.; Strohmann, C. Construction of $1 D$ and 2D copper(I) coordination polymers assembled by $\mathrm{PhS}\left(\mathrm{CH}_{2}\right)_{n} \mathrm{SPh}(\mathrm{n}=1,2)$ dithioether Ligands: surprising effect of the spacer length on the dimensionality, cluster nuclearity and the fluorescence properties of the metal-organic framework. Eur. J. Inorg. Chem. 2007, 1823-1828.

94. Blake, A. J.; Brooks, N. R.; Champness, N. R.; Crew, M.; Gregory, D. H.; Hubberstey, P.; Schroder, M.; Deveson, A.; Fenske, D.; Hanton, L. R. Topological isomerism in coordination polymers. Chem. Commun. 2001, 1432-1433.

95. Heller, M. A novel huge diamond-like three-fold interpenetrated network of CuI and crown ether. Z. Anorg, Allg. Chem. 2006, 632, 441-444.

96. Zhang, J.; Xue, Y.-S.; Li, Y.-Z.; Du, H.-B.; You, X.-Z. Cuprous iodide coordination polymers $(\mathrm{CuI})_{\mathrm{x}}(\mathrm{L})_{\mathrm{y}} . z$ (solvent) built on linear thioether linkers. CrystEngComm 2011, 13, 25782585. 
97. Henline, K. M.; Wang, C.; Pike, R. D.; Ahern, J. C.; Sousa, B.; Patterson, H. H.; Kerr, A. T.; Cahill, C. L. Structure, Dynamics, and Photophysics in the Copper(I) IodideTetrahydrothiophene System. Crystal Growth \& Design 2014, 14, 1449-1458.

98. Bowmaker, G. A.; Knappstein, R. J.; Tham, S. F. Infrared and Raman Spectroscopic study of some groupe $1 \mathrm{~B}$ halide complexes containing an $\mathrm{M}_{4} \mathrm{X}_{4}$ core Aust. J. Chem. 1978, 31, 2137-2143.

99. Turcotte, M.; Harvey, P. D. Characterization of the $\left\{\operatorname{Ag}(\mathrm{dmb})_{2}{ }^{+}\right\}_{n}$ Oligomers $(\mathrm{dmb}=1,8-$ Diisocyano-p-menthane) in Solution. Inorg. Chem. 2002, 41, 2971-2974.

100. Wyckoff, R. W. G.; Posnjak, E. The crystal structures of the cuprous halides. J. Am. Chem. Soc. 1922, 44, 30-36.

101. Kim, T. H.; Yang, H.; Park, G.; Lee, K. Y.; Kim, J. gamma-Cul Nanocrystals from SelfAssembled Coordination Polymers. Chem. Asian J. 2010, 5, 252-255.

102. Zhou, J.; Bian, G.-Q.; Dai, J.; Zhang, Y.; Zhu, Q.-Y.; Lu, W. Luminescent 2-D doublelayered polymer, $(\mathrm{CuI})_{4}\left(\mathrm{CH}_{3} \mathrm{SCH}_{3}\right)_{3} \infty$, containing helical chains constructed by flower-basketshaped $\mathrm{Cu}_{4} \mathrm{I}_{4}$ clusters. Inorg. Chem. 2006, 45, 8486-8488.

103. Knorr, M.; Pam, A.; Khatyr, A.; Strohmann, C.; Kubicki, M. M.; Rousselin, Y.; Aly, S. M.; Fortin, D.; Harvey, P. D. Reactivity of $\mathrm{Cul}$ and $\mathrm{CuBr}$ toward $\mathrm{Et}_{2} \mathrm{~S}$ : a Reinvestigation on the Self-Assembly of Luminescent Copper(I) Coordination Polymers. Inorg. Chem. 2010, 49, 58345844 .

SYNOPSIS

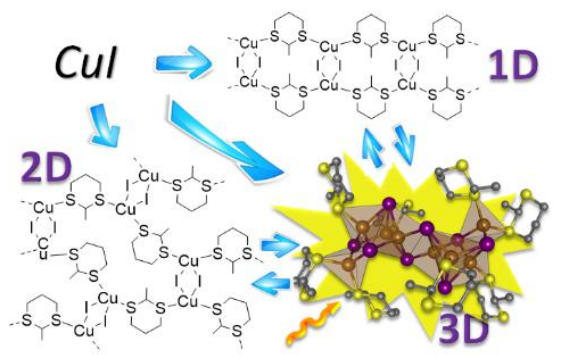

Graphic art 
A quasi-predictable design of a luminescent $3 \mathrm{D}$ CP containing a $\mathrm{Cu}_{8} \mathrm{I}_{8}$ cluster, consisting of an unprecedented open dicubane, is made. Furthermore, the interconversion between 1D, 2D and 3D networks has been investigated. 